Active behaviour change safety interventions in the construction industry:

A systematic review

Active behaviour change safety interventions in the construction industry: A systematic review

Authors: Barbara Mullan ${ }^{\mathrm{a}, \mathrm{b}}$, Lauren Smith ${ }^{\mathrm{a}}$, Kirby Sainsbury ${ }^{\mathrm{b}}$, Vanessa Allom ${ }^{\mathrm{b}}$, Helen Paterson $^{\mathrm{a}}$, Anna-Lena Lopez ${ }^{\mathrm{a}}$

${ }^{\text {a }}$ School of Psychology, The University of Sydney, Sydney, NSW, Australia

${ }^{\mathrm{b}}$ School of Psychology and Speech Pathology, Curtin University, Perth, WA, Australia 


\title{
Active behaviour change safety interventions in the construction industry:
}

\section{A systematic review}

\begin{abstract}
The aims of this paper were to systematically review the evidence for the effectiveness of active behaviour change safety interventions in the construction industry; and to determine the intervention characteristics most commonly associated with effectiveness in reducing injury rates and improving safety behaviour - intensity/frequency/duration, behaviour change techniques (BCTs) and theory-base. An electronic literature search (June 2014) was conducted to identify eligible interventions: those involving active involvement from workers/management in the construction industry; targeted one/both of the primary outcomes. All intervention designs involving construction workers aged $>18$ years, published in English and in a peer-reviewed journal were included. Fifteen studies were included, half of which successfully improved injury rates. Longer interventions and those that included active/volitional BCTs (feedback/monitoring rather than instruction/information) were more effective. The methodological quality of the interventions was poor and use of theory was inconsistent and infrequent. Despite some positive results, very few interventions achieved all their aims. More rigorous, theory-driven research is needed to structure intervention efforts and determine the mechanism of action of effective interventions.
\end{abstract}

Keywords: Systematic review, construction, injury/accident prevention, safety, behaviour change techniques 


\section{Active behaviour change safety interventions in the construction industry:}

\section{A systematic review}

\section{INTRODUCTION}

Workplace injuries are widespread; in the UK from 2010-2011 nearly 150 people were killed in workplace accidents, 27 million working days were lost, and societal costs approximated $£ 14$ billion (Health and Safety Executive, 2013). In the USA, the cost of all work-related injuries in 2011 was $\$ 189$ billion (National Safety Council, 2013). The construction industry ranks as one of the highest for work-related injuries (International Labour Organization, 2011), accounting for $27 \%$ of fatal injuries and $10 \%$ of major injuries in the UK, despite representing only $5 \%$ of workers. In the USA in 2002 , costs of injuries in the construction industry were estimated to be $\$ 11.5$ billion.

A 2008 review of construction-related injuries interventions identified only five eligible studies (Lehtola et al., 2008). The major finding was that the introduction of safety legislation alone was not effective in reducing injuries (Lehtola et al., 2008). The remaining interventions were effective but poor methodological quality and significant heterogeneity meant that the means by which these interventions changed behaviour was unclear. In an updated review in 2012 (13 studies; van der Molen et al., 2012), it was similarly concluded that there was no evidence that the introduction of safety legislation/regulations alone or that regionally-oriented interventions such as inspections or training were effective in reducing injuries. There was, however, low-level evidence that company-oriented interventions (e.g., multifaceted safety campaign, drug-free workplace) resulted in reduced injuries (van der Molen et al., 2012). Another review of three interventions specifically to reduce falls in the construction industry also found limited evidence for effectiveness (Rivara \& Thompson, 2000).

The purpose of the present review was to extend the previous reviews (Lehtola et al., 2008; van der Molen et al., 2012), firstly by including interventions that targeted safety 


\section{Active behaviour change safety interventions in the construction industry:}

\section{A systematic review}

behaviours in addition to those that solely measured injury rates; and secondly, by focusing more explicitly on the intervention characteristics (e.g., use of theory, behaviour change techniques (BCTs), and intensity/frequency/duration) that were most commonly associated with effectiveness. Indeed, this was identified as a limitation of the previous review (van der Molen et al., 2012) and thus represents an important research question. Given the lack of evidence for the effectiveness of legislation in reducing injuries (Lehtola et al., 2008; van der Molen et al., 2012), the specific focus of the current review was on interventions that actively involved workers or management in changing their behaviour. Thus, interventions that involved legislation/regulations or environmental modifications as their sole method of changing behaviour were excluded. Additional impetus for this work comes from research demonstrating that behaviour change interventions are more effective if they are based on a theoretical understanding of the behaviour, and are designed using theory to select the BCTs with which to target relevant factors (Webb, Joseph, Yardley, \& Michie, 2010). Indeed, several theory-based interventions in other health-related behaviours developed using this method have been shown to be effective (Kothe, Mullan, \& Butow, 2012; Milton \& Mullan, 2012; Sainsbury, Mullan, \& Sharpe, 2013).

\subsection{Research questions}

- What active/behaviourally-focused safety interventions have been conducted in the construction industry?

- What is the effectiveness of these safety interventions in: (1) reducing the incidence of injuries; (2) prompting improvements in safety behaviours, which may, in turn, reduce injuries (e.g., increased use of personal protective equipment or adherence to safety regulations)?

- Was effectiveness related to the frequency, intensity, or duration of the interventions? 


\section{Active behaviour change safety interventions in the construction industry:}

\section{A systematic review}

- What theoretical basis, if any, underpins these interventions?

- Were particular BCTs more strongly related to effectiveness than others?

- What is the quality of the evidence reviewed?

\section{METHOD}

\subsection{Search Strategy}

In June 2013 (updated in June 2014) a systematic literature review was conducted based on the PRISMA guidelines (Moher, Liberati, Tetzlaff, \& Altman, 2009) and the Cochrane Handbook for Systematic Reviews of Interventions (Higgins \& Green, 2011). Electronic literature searches were performed in PsychINFO, Medline, Web of Science, and PubMed. Key word search terms included the following: (Injuries OR Industrial Accidents OR Occupational Injury) AND (Health Promotion OR Accident Prevention OR Injury prevention) AND (Intervention study OR Intervention research); (Construction) AND (Health Promotion OR Accident Prevention OR Injury Prevention) AND (Occupational Safety OR Work Safety).

\subsection{Eligibility criteria}

All peer-reviewed studies including randomised-controlled trials (RCTs), clusterRCTs, controlled pre-post studies, and interrupted time-series (a design in which data is collected over a period of time, including prior to the introduction of an intervention, in order to determine whether the introduction led to changes over and above any existing trends over time; Ramsay, Matowe, Grilli, Grimshaw, \& Thomas, 2003) were eligible for inclusion. There was no specific time-based (pre- or post-introduction of intervention) criterion for the inclusion of interrupted time-series studies. Only studies in English were included. The target population consisted of adult (aged $>18$ years) workers in construction and constructionrelated industries (e.g., metal workers, tilers, roofers, road workers, and labourers). Eligible 


\section{Active behaviour change safety interventions in the construction industry:}

\section{A systematic review}

studies were interventions in which construction workers or management actively participated, conducted in a real-life setting, and that targeted injury rates within the workplace and/or the uptake of safety behaviours. Passive interventions (e.g., introduction of safety legislation/regulations or environmental modifications/ equipment) without an active training component were excluded.

Extracted data included type of construction, participant and intervention characteristics, study design, control/comparison group, injury type/safety behaviour targeted, and results. Studies were coded for their use of a theoretical framework (theory-based vs. non-theory-based), and intervention descriptions were examined and coded for the use of BCTs using 'The BCTs Taxonomy (v1)' (Michie et al., 2013) which contains 93 BCTs within 16 broad clusters (e.g., knowledge shaping, rewards and threat, feedback and monitoring).

\subsection{Study selection}

Two of the authors independently screened all identified records by title. Articles deemed eligible or cases where a decision could not be made were then screened by abstract and full-text, with any disagreements resolved through discussion. Reference lists of the final articles and papers identified in the previous reviews (Lehtola et al., 2008; van der Molen et al., 2012) were manually examined.

\subsection{Assessment of risk of bias in included studies}

The methodological quality of each study was independently assessed using either the Downs and Black Internal Validity Criteria Checklist (randomised and pre-post studies; Downs \& Black, 1998) or the Cochrane Effective Practice and Organisation of Care review group's Quality Criteria Checklist (interrupted time-series studies; EPOC, 2009). Based on a 


\section{Active behaviour change safety interventions in the construction industry:}

\section{A systematic review}

lack of similarity between studies regarding design, sample, and outcome measures it was not possible to conduct a meta-analysis (Higgins \& Green, 2008).

\section{RESULTS}

\subsection{Study selection}

The search strategy yielded 6355 hits (see Figure 1), of which, 13 met the inclusion criteria. Agreement between the two reviewers was high at both the title (95.8\%), and abstract (96.2\%), stages. Examination of the 13 reference lists and assessment of the degree of overlap with previous reviews (Lehtola et al., 2008; van der Molen et al., 2012), yielded an additional 11 studies, two of which met criteria. Thus, fifteen studies were included in the review (see Table 1 for a summary of sample and intervention characteristics). Reasons for exclusion included: the intervention did not involve active BCTs (Aires, Gamez, \& Gibb, 2010; Beal, 2007; Lipscomb, Li, \& Dement, 2003; Mirka, Monroe, Nay, Lipscomb, \& Kelaher, 2003; Mohr \& Clemmer, 1989; Saruda, Whitaker, Bloswick, Philips, \& Sesek, 2002), published in a language other than English (Miscetti \& Bodo, 2008) and not published in a peer-reviewed journal (Tyers et al., 2007). 


\section{Active behaviour change safety interventions in the construction industry:}

\section{A systematic review}
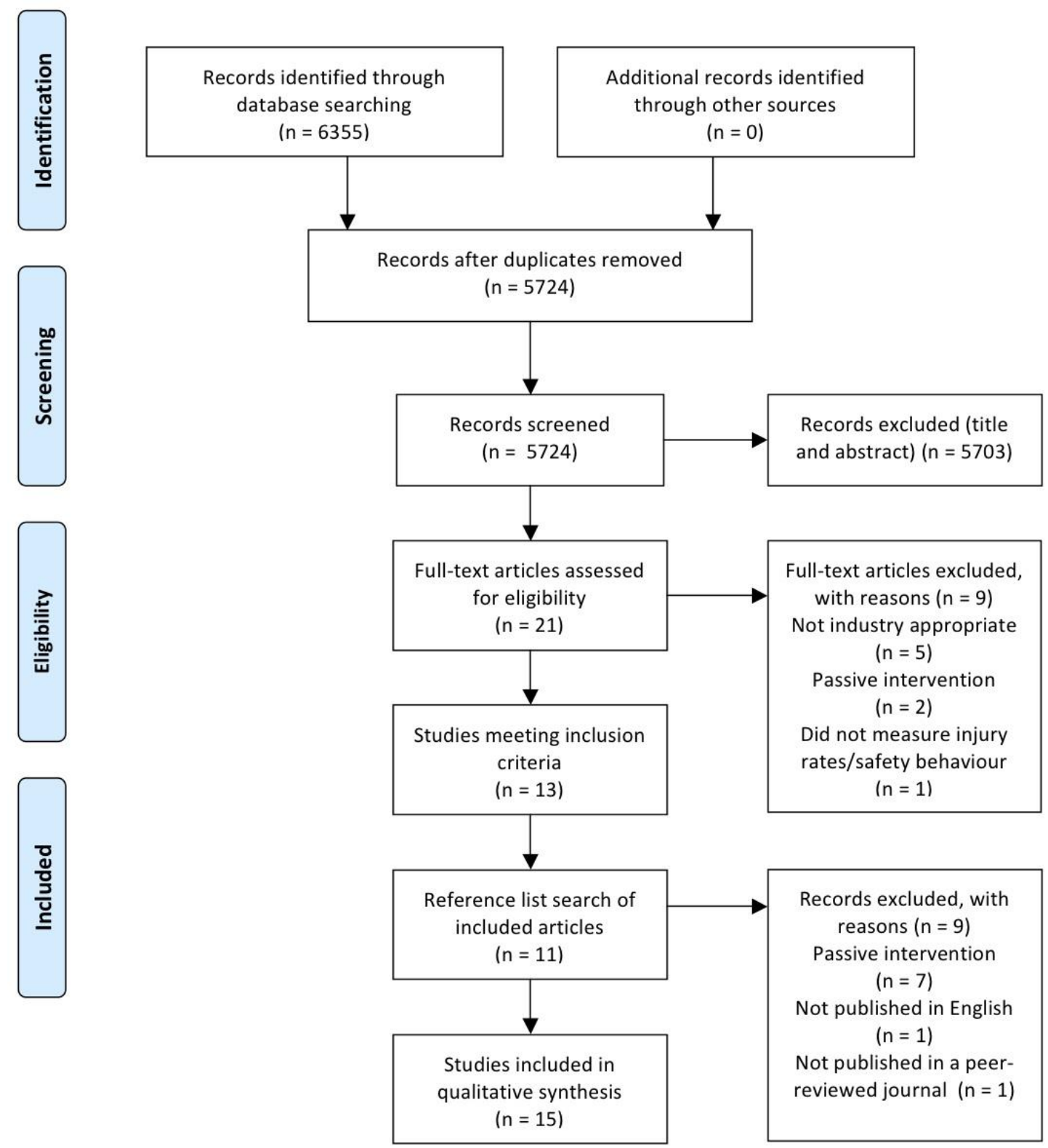

Figure 1. Flow Diagram of study selection

\subsection{Study characteristics}

Reported sample sizes ranged from 175 to 507262; in eight studies the exact sample size was not reported either because the number of workers present for each day/session of the intervention period differed, or the number of work sites rather than participants was 


\section{Active behaviour change safety interventions in the construction industry:}

\section{A systematic review}

reported (see Supplementary Table 1 for detailed descriptions of each study including intervention and control group materials). The type of construction work varied, from specific trades (e.g., carpentry, roofing, tiling, concrete, floor laying) to larger scale industries (e.g., metal/steel/aluminium work, stone quarry, railways). Six studies were conducted in the USA (Becker, Fullen, Akladios, \& Hobbs, 2001; Darragh, Stallones, Bigelow, \& Keefe, 2004; Forst et al., 2013; Kerr, Savik, Monsen, \& Lusk, 2007; Lusk et al., 1999; Sokas, Jorgensen, Nickels, Gao, \& Gittleman, 2009), three in Denmark (Kines, Andersen, Andersen, Nielsen, \& Pedersen, 2013; Kines et al., 2010; Spangenberg, Mikkelsen, Kines, Dyreborg, \& Baarts, 2002), two in Italy (Bena, Berchialla, Coffano, Debernardi, \& Icardi, 2009; Mancini et al., 2005), and one each in Hong Kong (Lingard \& Rowlinson, 1997), India (Adams et al., 2013), Spain (Lopez-Ruiz et al., 2013), and Finland (Laitinen \& Päivärinta, 2010).

Only one study employed a conventional RCT design where the unit of randomisation was the individual (Kerr et al., 2007). A further three studies used a cluster-RCT design where the unit of randomisation was the construction company/site (Kines et al., 2013; Kines et al., 2010; Spangenberg et al., 2002); and one study used a four-group Solomon design with participants randomised by naturally occurring training groups (Lusk et al., 1999). Two studies used a pre-post design with a control group but were not classified as RCTs due to non-random assignment to conditions (Becker et al., 2001) or comparison with non-matched convenience samples (Mancini et al., 2005). Two studies used a pre-post design with no control group (Forst et al., 2013; Sokas et al., 2009); three studies used an interrupted timeseries design with (Laitinen \& Päivärinta, 2010) or without a control group (Darragh et al., 2004; Spangenberg et al., 2002); and two studies used a mixed-approach including both pre-

post and time-series analyses with (Lopez-Ruiz et al., 2013) or without a control group (Bena et al., 2009). The final study employed a within-groups design where four different 


\section{Active behaviour change safety interventions in the construction industry:}

\section{A systematic review}

behaviours were targeted in a staggered fashion and the same group of participants served as the intervention and control groups (Lingard \& Rowlinson, 1997).

Two studies reported on both injury rates and the uptake of safety behaviours (Adams et al., 2013; Laitinen \& Päivärinta, 2010). Five studies reported on injury rates alone (Bena et al., 2009; Darragh et al., 2004; Lopez-Ruiz et al., 2013; Mancini et al., 2005; Spangenberg et al., 2002), and eight studies reported on the uptake of safety behaviours alone (Becker et al., 2001; Forst et al., 2013; Kerr et al., 2007; Kines et al., 2013; Kines et al., 2010; Lingard \& Rowlinson, 1997; Lusk et al., 1999; Sokas et al., 2009). Most studies measured general/overall injuries (Bena et al., 2009; Darragh et al., 2004; Laitinen \& Päivärinta, 2010; Lopez-Ruiz et al., 2013; Spangenberg et al., 2002), although two focused specifically on eye/ocular injuries (Adams et al., 2013; Mancini et al., 2005). Safety behaviours targeted included: falls prevention practices (Becker et al., 2001; Sokas et al., 2009), electrical safety hazard practices (Sokas et al., 2009), compliance with protective eyewear (Adams et al., 2013; Mancini et al., 2005), use of hearing protection devices (Kerr et al., 2007; Lusk et al., 1999), and safety-related communication.(Kines et al., 2010) Several studies used a general/overall measure of safety behaviour such as a safety index, which included the rating of various safety behaviours (Kines et al., 2013; Laitinen \& Päivärinta, 2010; Lingard \& Rowlinson, 1997) - for example, use of personal protective equipment (Kines et al., 2013; Lingard \& Rowlinson, 1997), scaffolding (Laitinen \& Päivärinta, 2010; Lingard \& Rowlinson, 1997), and housekeeping (Lingard \& Rowlinson, 1997) or order and tidiness (Kines et al., 2013; Laitinen \& Päivärinta, 2010).

Interventions used a range of methods to change behaviour including educational/information sessions (Adams et al., 2013; Bena et al., 2009; Darragh et al., 2004; Forst et al., 2013; Sokas et al., 2009), the distribution of educational material (e.g., booklet, 


\section{Active behaviour change safety interventions in the construction industry:}

\section{A systematic review}

TV broadcasts; Darragh et al., 2004; Lusk et al., 1999; Mancini et al., 2005; Spangenberg et al., 2002), site inspections/audits/follow-up visits (Adams et al., 2013; Becker et al., 2001; Laitinen \& Päivärinta, 2010; Lopez-Ruiz et al., 2013), coaching (Kines et al., 2010), goal setting (Lingard \& Rowlinson, 1997), problem solving (Kines et al., 2013), providing feedback (Kines et al., 2010; Lingard \& Rowlinson, 1997; Spangenberg et al., 2002), and administrative strategies such as management meetings, warning letters, and the development of recommendations and sanctions (Lopez-Ruiz et al., 2013; Spangenberg et al., 2002). One study involved participants playing a computer game that incorporated health messages (Kerr et al., 2007); and two consisted of a safety campaign (Spangenberg et al., 2002) or contest (Laitinen \& Päivärinta, 2010) between different construction companies/sites, both of which employed incentives and penalties.

\subsection{Intervention Effectiveness}

\subsubsection{Injury Rates}

Amongst the seven relevant studies, two found a significant improvement/reduction in injuries relative to the control group (Lopez-Ruiz et al., 2013; Mancini et al., 2005). Notably, however, in the former study, the intervention and control groups were non-equivalent at baseline as assignment to the intervention condition was based on having elevated injury rates in the period prior to the intervention being introduced, while the control condition included companies with any level of injury rates (Lopez-Ruiz et al., 2013). While ethically it was probably necessary to target those sites, methodologically this design makes it difficult to draw firm conclusions about the effectiveness of the intervention as injury rate at baseline was not controlled for. Similarly in another study, the injury reduction rate in the contest region was greater than for the corresponding time period in the non-contest/comparison region; however, the absolute injury rate remained higher than in the comparison region 


\section{Active behaviour change safety interventions in the construction industry:}

\section{A systematic review}

(Laitinen \& Päivärinta, 2010). Another study found that although there was an overall significant decrease in injury rates from baseline to post-intervention, the difference between the two intervention groups (standard education vs. enhanced education) was not significant (Adams et al., 2013). This study did not, however, include a no-treatment control group and did not utilise a time-series analysis so it is not possible to determine whether the reduction in injuries observed was greater than any existing secular trend. Indeed, a further two studies utilising a single sample within-group design showed a significant reduction in injury rates using pre-post analyses; however, the time-series analyses failed to confirm this pattern (Bena et al., 2009; Darragh et al., 2004). The final time-series study found that injuries decreased following the introduction of the intervention; however, the reduction was only significant when controlling for the type of construction, with light construction work having lower injury rates than heavy construction work (Spangenberg et al., 2002).

\subsubsection{Uptake of Safety Behaviours}

Of the ten relevant studies four found a significant improvement in behaviour compared to the control group: improved safety audit scores (Becker et al., 2001), use of hearing protective devices (Lusk et al., 1999), safety knowledge, safety involvement (Kines et al., 2013), safety-related communication, and safety performance (overall score; Kines et al., 2010). Five further studies found significant improvements from baseline to postintervention in compliance with protective eyewear (Adams et al., 2013), the use of hearing protection devices, benefits/barriers, self-efficacy (Kerr et al., 2007), knowledge (Forst et al., 2013; Sokas et al., 2009), and safety indices (overall score; Laitinen \& Päivärinta, 2010). In this latter study the observed improvements plateaued during the one year that the contest did not run, and resumed when the contest was reintroduced the following year (Laitinen \& Päivärinta, 2010). Similarly, one study used a within-group design and found significant 


\section{Active behaviour change safety interventions in the construction industry:}

\section{A systematic review}

improvements in housekeeping safety, which decreased again following removal of the intervention (Lingard \& Rowlinson, 1997).

Two of the above studies stated in their methods that they had measured "selfreported safety behaviour" (Sokas et al., 2009) or "behavioural change" (Forst et al., 2013) but then only reported results concerning attitudes and/or knowledge, so it was not possible to determine the effect of the intervention on actual safety behaviour. Finally, although not directly analysed, the findings of two of the above studies in which both injury rates and safety behaviours were assessed suggested that improvements in safety behaviour were successfully translated into reduced injury rates (Adams et al., 2013; Laitinen \& Päivärinta, 2010).

Overall, despite mixed results in many of the studies, all relevant interventions resulted in improvements in at least one safety behaviour/outcome. For this reason and given the variability in behavioural measures and design, it was not possible to calculate effect sizes, and nor did any of the papers report effect sizes. Unfortunately, this meant that comprehensive comparisons according to intensity/duration/frequency, theoretical basis, and use of BCTs could not be conducted for the safety behaviour studies.

\subsection{Intensity, duration, and frequency of the interventions}

Seven of the interventions were delivered over either one (Adams et al., 2013; Darragh et al., 2004; Kerr et al., 2007; Lusk et al., 1999) or two sessions (Bena et al., 2009; Forst et al., 2013; Sokas et al., 2009), one of which also included follow-up visits for six months (Adams et al., 2013). Another four involved the active delivery of intervention components for between eight and 26 weeks (Kines et al., 2013; Kines et al., 2010; Lingard \& Rowlinson, 1997; Mancini et al., 2005), while four involved ongoing monitoring/inspections for between one-and-a-half and four years (Becker et al., 2001; 


\section{Active behaviour change safety interventions in the construction industry:}

\section{A systematic review}

Laitinen \& Päivärinta, 2010; Lopez-Ruiz et al., 2013; Spangenberg et al., 2002). Amongst the interventions that measured injury rates (Adams et al., 2013; Bena et al., 2009; Darragh et al., 2004; Laitinen \& Päivärinta, 2010; Lopez-Ruiz et al., 2013; Mancini et al., 2005;

Spangenberg et al., 2002), those that were delivered over an extended time period were more likely to be effective (all four resulted in significant reductions, although one only when controlling for light vs. heavy construction work; Laitinen \& Päivärinta, 2010; Lopez-Ruiz et al., 2013; Mancini et al., 2005; Spangenberg et al., 2002) than those that involved only one or two sessions (1/4 resulted in a significant reduction in pre-post analyses, although the timeseries analysis was non-significant; Bena et al., 2009). In the study that involved the comparison of a standard and enhanced educational program, there were reductions in injuries in both groups over the six-month study period (7\% and $12 \%$ respectively), but the difference between them did not reach statistical significance (Adams et al., 2013).

\subsection{Theoretical Basis of the Interventions}

Five interventions were based on theory - namely, the PRECEDE-PROCEED model (Bena et al., 2009), Goal Setting Theory (Lingard \& Rowlinson, 1997), Integrated Safety Management Theory (Kines et al., 2013), the Health Promotion Model (Lusk et al., 1999), and the Predictors of Use of Hearing Protection Model (Kerr et al., 2007). Use of theory was inconsistent. In only one of the five theory-based interventions were the components of the theory measured at baseline and post-intervention and used to test the model (Kerr et al., 2007). Here it was shown that the theoretical variables of past behaviour, social models, and benefits/barriers accounted for $58 \%$ of the variance in the use of hearing protection devices at post-intervention (Kerr et al., 2007). In one study the theory was used to conduct formative research to identify the determinants of accident/injury risk and inform the intervention targets (Bena et al., 2009), and in the other three studies it was suggested that the theory 
Active behaviour change safety interventions in the construction industry:

A systematic review

informed the intervention targets and/or methods but this was not clearly reported or measured (Kines et al., 2013; Lingard \& Rowlinson, 1997; Lusk et al., 1999). 


\section{Active behaviour change safety interventions in the construction industry:}

\section{A systematic review}

Table 1. Theoretical basis and behaviour change techniques used in interventions

\begin{tabular}{|c|c|c|c|c|c|}
\hline Study & Theory & $\begin{array}{l}\text { Shaping knowledge/ natural } \\
\text { consequences }\end{array}$ & $\begin{array}{l}\text { Feedback and monitoring/ } \\
\text { goals and planning }\end{array}$ & $\begin{array}{l}\text { Rewards and threat } \\
\text { and/or scheduled } \\
\text { consequences }\end{array}$ & Other BCTs \\
\hline $\begin{array}{l}\text { Adams et al., } \\
(2013) \text {. }\end{array}$ & Nil & $\begin{array}{l}\text { Provide instruction on how to } \\
\text { perform the behaviour; } \\
\text { Information about health } \\
\text { consequences. }\end{array}$ & & & $\begin{array}{l}\text { Social support (emotional; } \\
\text { includes motivational } \\
\text { interviewing) }\end{array}$ \\
\hline $\begin{array}{l}\text { Becker et al., } \\
(2001) \text {. }\end{array}$ & Nil & & $\begin{array}{l}\text { Monitoring of outcomes of } \\
\text { behaviour without feedback. }\end{array}$ & Incentive (outcome). & \\
\hline Bena et al., (2009). & $\begin{array}{l}\text { Precede- } \\
\text { Proceed }\end{array}$ & $\begin{array}{l}\text { Instruction on how to perform } \\
\text { the behaviour; Information } \\
\text { about health consequences; } \\
\text { Salience of consequences. }\end{array}$ & Feedback on behaviour. & & \\
\hline $\begin{array}{l}\text { Darragh et al., } \\
\text { (2004). }\end{array}$ & Nil & $\begin{array}{l}\text { Provide instruction on how to } \\
\text { perform the behaviour. }\end{array}$ & & $\begin{array}{l}\text { Material reward } \\
\text { (behaviour); Incentive } \\
\text { (outcome). }\end{array}$ & \\
\hline Forst et al., (2013). & Nil & $\begin{array}{l}\text { Provide instruction on how to } \\
\text { perform the behaviour. }\end{array}$ & & & $\begin{array}{l}\text { Demonstration of the } \\
\text { behaviour; Identification of } \\
\text { self as a role model. }\end{array}$ \\
\hline Kerr et al., (2007). & $\begin{array}{l}\text { Health } \\
\text { Promotion } \\
\text { Model: } \\
\text { Predictors of } \\
\text { Use of } \\
\text { Hearing } \\
\text { Protection } \\
\text { Model } \\
\text { (PUHPM) }\end{array}$ & $\begin{array}{l}\text { Information about health } \\
\text { consequences. }\end{array}$ & & & $\begin{array}{l}\text { Behavioural } \\
\text { practice/rehearsal. }\end{array}$ \\
\hline Kines et al., (2013). & $\begin{array}{l}\text { Integrated } \\
\text { Safety } \\
\text { Management } \\
\text { Theory }\end{array}$ & & $\begin{array}{l}\text { Goal setting (behaviour); Goal } \\
\text { setting (outcome); Problem } \\
\text { solving; Review behavioural } \\
\text { goals. }\end{array}$ & & \\
\hline
\end{tabular}


Active behaviour change safety interventions in the construction industry:

\section{A systematic review}

\begin{tabular}{|c|c|c|c|c|c|}
\hline Kines et al., (2010). & Nil & $\begin{array}{l}\text { Provide instruction on how to } \\
\text { perform the behaviour. }\end{array}$ & Feedback on behaviour. & & $\begin{array}{l}\text { Behavioural } \\
\text { practice/rehearsal. }\end{array}$ \\
\hline $\begin{array}{l}\text { Laitinen \& } \\
\text { Päivärinta (2010) }\end{array}$ & Nil & & Monitoring of outcomes of & Social reward/incentive; & \\
\hline Lingard \& & Goal setting & & Goal setting (behaviour); & & \\
\hline Rowlinson (1997). & theory & & Feedback on behaviour. & & \\
\hline $\begin{array}{l}\text { Lopez-Ruiz et al., } \\
\text { (2013). }\end{array}$ & Nil & & $\begin{array}{l}\text { Monitoring of behaviour } \\
\text { without feedback; Monitoring } \\
\text { of outcomes of behaviour } \\
\text { without feedback. }\end{array}$ & Punishment. & \\
\hline Lusk et al., (1999). & $\begin{array}{l}\text { Health } \\
\text { Promotion } \\
\text { Model } \\
\text { (derived from } \\
\text { social learning } \\
\text { theory). }\end{array}$ & $\begin{array}{l}\text { Provide instruction on how to } \\
\text { perform the behaviour; } \\
\text { Information about health } \\
\text { consequences. }\end{array}$ & & & $\begin{array}{l}\text { Demonstration of the } \\
\text { behaviour; Credible source. }\end{array}$ \\
\hline $\begin{array}{l}\text { Mancini et al., } \\
\text { (2005). }\end{array}$ & Nil & $\begin{array}{l}\text { Instruction on how to perform } \\
\text { the behaviour; Information of } \\
\text { health consequences; Salience } \\
\text { of consequences. }\end{array}$ & $\begin{array}{l}\text { Monitoring of behaviour } \\
\text { without feedback. }\end{array}$ & & Credible source. \\
\hline $\begin{array}{l}\text { Sokas et al., } \\
\text { (2009). }\end{array}$ & Nil & $\begin{array}{l}\text { Information about health } \\
\text { consequences. }\end{array}$ & & $\begin{array}{l}\text { Material reward } \\
\text { (behaviour). }\end{array}$ & Behavioural practice/reward. \\
\hline $\begin{array}{l}\text { Spangenberg et al., } \\
(2002) \text {. }\end{array}$ & Nil & $\begin{array}{l}\text { Provide instruction on how to } \\
\text { perform the behaviour. }\end{array}$ & $\begin{array}{l}\text { Feedback on outcome of } \\
\text { behaviour. }\end{array}$ & $\begin{array}{l}\text { Incentive (outcome); } \\
\text { Reward (outcome); } \\
\text { Behaviour cost. }\end{array}$ & \\
\hline
\end{tabular}




\section{Active behaviour change safety interventions in the construction industry:}

\section{A systematic review}

\subsection{Use of BCTs}

BCTs included in the interventions fell under the broad categories of feedback and monitoring (8 studies; Becker et al., 2001; Bena et al., 2009; Kines et al., 2010; Laitinen \& Päivärinta, 2010; Lingard \& Rowlinson, 1997; Lopez-Ruiz et al., 2013; Mancini et al., 2005; Spangenberg et al., 2002), shaping knowledge (8 studies; Adams et al., 2013; Bena et al., 2009; Darragh et al., 2004; Forst et al., 2013; Kines et al., 2010; Lusk et al., 1999; Mancini et al., 2005; Spangenberg et al., 2002), natural consequences (6 studies; Adams et al., 2013; Bena et al., 2009; Kerr et al., 2007; Lusk et al., 1999; Mancini et al., 2005; Sokas et al., 2009), reward and threat (5 studies; Becker et al., 2001; Darragh et al., 2004; Laitinen \& Päivärinta, 2010; Sokas et al., 2009; Spangenberg et al., 2002), repetition and substitution (3 studies; Kerr et al., 2007; Kines et al., 2010; Sokas et al., 2009), goals and planning (Kines et al., 2013; Lingard \& Rowlinson, 1997), comparison of outcomes (Lusk et al., 1999; Mancini et al., 2005), scheduled consequences (Lopez-Ruiz et al., 2013; Spangenberg et al., 2002), social support, ${ }^{33,37}$ comparison of behaviour (Forst et al., 2013; Lusk et al., 1999; 2 studies each), and identity (1 study; Forst et al., 2013). Interventions used between one and five distinct BCTs; the number of BCTs used did not appear to be related to effectiveness.

In order to determine the BCTs most commonly associated with effectiveness, interventions were coded in three ways according to the inclusion of BCTs from each of the following broad categories, as specified in the BCT taxonomy v1 (Michie et al., 2013). These particular categories were selected and grouped together based on the frequency of use within the interventions, as well as distinguishing between the 


\section{Active behaviour change safety interventions in the construction industry:}

\section{A systematic review}

1 particular change targets (i.e., attitudes/knowledge vs. volitional control and

2 intrinsic/extrinsic motivation for behaviour).

- Shaping knowledge and/or natural consequences;

- Feedback and monitoring and/or goals and planning;

- Rewards and threat and/or scheduled consequences.

The interventions that used BCTs from the categories 'shaping knowledge' (predominantly instruction on how to perform the behaviour) and/or 'natural consequences' (predominantly information about health consequences) as their main method of changing behaviour were less likely to result in significant reductions in injury rates than those that did not include these techniques. Specifically, of the five studies that included 'shaping knowledge'/'natural consequences' and targeted injury rates (Adams et al., 2013; Bena et al., 2009; Darragh et al., 2004; Mancini et al., 2005; Spangenberg et al., 2002), only one showed a significant reduction in injury rates (Mancini et al., 2005) compared to both studies that utilised alternate BCTs (e.g., rewards, incentives, punishment, feedback/monitoring; Laitinen \& Päivärinta, 2010; Lopez-Ruiz et al., 2013). It should, however, be noted that amongst the former interventions (shaping knowledge/natural consequences), improvements were observed in pre-post analyses but were not significantly different to the lower intensity control group (standard education; Adams et al., 2013), time-series analyses failed to confirm the pattern (Bena et al., 2009; Darragh et al., 2004), or the reduction was only significant when controlling for other factors (light vs. heavy construction work; Spangenberg et al., 2002).

In contrast, interventions that included BCTs from the 'feedback and monitoring' (predominantly monitoring of behaviour/outcome without feedback, and 


\section{Active behaviour change safety interventions in the construction industry:}

\section{A systematic review}

1 feedback on behaviour) and/or 'goals and planning' (e.g., goal setting, problem

2 solving, and review behavioural goals) categories appeared more likely to be effective

3 in reducing injury rates (3/5 interventions effective; Laitinen \& Päivärinta, 2010;

4 Lopez-Ruiz et al., 2013; Mancini et al., 2005) than those that did not (neither

5 effective; Adams et al., 2013; Darragh et al., 2004). The two interventions that

6 included these techniques and had non-significant reductions did, however, evidence

7 improvements using pre-post analysis (Bena et al., 2009) and when controlling for

8 other factors (Spangenberg et al., 2002). Of the four former studies, three used

9 monitoring of behaviour/outcomes without feedback (Laitinen \& Päivärinta, 2010;

10 Lopez-Ruiz et al., 2013; Mancini et al., 2005), suggesting that knowledge of being

11 monitored/observed may be sufficient to change behaviour even when feedback on

12 that behaviour is not provided.

There was no clear difference in effectiveness between the studies that used

BCTs from the 'reward and threat' (e.g., material incentive/reward, social

incentive/reward) and/or 'scheduled consequences' (e.g., punishment) categories (2/4

effective; one other effective when controlling for light vs. heavy construction;

Laitinen \& Päivärinta, 2010; Lopez-Ruiz et al., 2013) and those that did not (1/3

effective; the other two evidenced reductions in pre-post analyses but time-series

failed to confirm/not significantly different to lower intensity control group; Mancini

et al., 2005). However, the only study that included these techniques but did not

21 include 'feedback and monitoring' techniques was not effective in improving injury

22 rates (Darragh et al., 2004), whereas the three that used BCTs from both categories

23 were effective (although one only when controlling for light vs. heavy; Laitinen \&

24 Päivärinta, 2010; Lopez-Ruiz et al., 2013; Spangenberg et al., 2002). 


\section{Active behaviour change safety interventions in the construction industry:}

\section{A systematic review}

None of the four studies that used 'repetition and substitution' (behavioural practice/rehearsal; Kerr et al., 2007; Kines et al., 2010; Lusk et al., 1999; Sokas et al., 2009) targeted injury rates and all used this strategy in addition to 'shaping knowledge' and/or 'natural consequences', meaning it was not possible to judge its effectiveness in isolation. The two studies that used 'comparison of outcomes' (credible source; Lusk et al., 1999; Mancini et al., 2005) were effective in improving safety behaviour and reducing injury rates respectively, but again this BCT was used in combination with others (e.g., shaping knowledge, natural consequences, monitoring and practice) so its effectiveness alone is unclear.

\subsection{Study quality}

The quality of interventions was variable and generally methodologically poor (see Tables 2 and 3). Amongst the ten randomised and non-randomised studies, four scored between 3-5 (maximum score of 11, higher scores indicate lower risk of bias; Becker et al., 2001; Bena et al., 2009; Forst et al., 2013; Sokas et al., 2009), four scored between 6-8 (Kines et al., 2010; Lopez-Ruiz et al., 2013; Lusk et al., 1999; Mancini et al., 2005), two scored 9 (Kerr et al., 2007; Kines et al., 2013), and only one achieved the maximum score (Adams et al., 2013). The four randomised studies (Adams et al., 2013; Kerr et al., 2007; Kines et al., 2013; Lusk et al., 1999) were generally of higher quality than the non-randomised studies, with only one scoring in the lower ranges (Lusk et al., 1999). The main bias-related issue identified was the failure to blind participants and assessors to the intervention (Kerr et al., 2007; Kines et al., 2013; Lusk et al., 1999); this was similar for the six non-randomised studies (Becker et al., 2001; Bena et al., 2009; Forst et al., 2013; Kines et al., 2010; LopezRuiz et al., 2013; Mancini et al., 2005; Sokas et al., 2009). Additional issues identified 


\section{Active behaviour change safety interventions in the construction industry:}

\section{A systematic review}

1 included the failure to account for loss-to-follow-up or unclear reporting (Becker et

2 al., 2001; Bena et al., 2009; Forst et al., 2013; Lopez-Ruiz et al., 2013; Mancini et al.,

3 2005), compromised compliance with the intervention (Becker et al., 2001; Bena et

4 al., 2009; Mancini et al., 2005), and failure to recruit participants from the same

5 population or over the same time period (Bena et al., 2009; Forst et al., 2013; Lusk et

6 al., 1999; Sokas et al., 2009).

7 Of the six interrupted time-series interventions (two also included in above

8 assessment because they combined pre-post and time-series analyses), three studies

9 scored 3 (maximum score of 6, higher scores indicate lower risk of bias; Darragh et

10 al., 2004; Laitinen \& Päivärinta, 2010; Spangenberg et al., 2002), and the other three

11 studies scored 4 (Bena et al., 2009; Lingard \& Rowlinson, 1997; Lopez-Ruiz et al.,

12 2013). The main identified issues were a high or unclear risk of bias concerning the

13 intervention being independent of other changes or selective/other biases (Bena et al.,

14 2009; Darragh et al., 2004; Laitinen \& Päivärinta, 2010; Lingard \& Rowlinson, 1997;

15 Lopez-Ruiz et al., 2013; Spangenberg et al., 2002), and incompleteness of the data set

16 (Darragh et al., 2004; Laitinen \& Päivärinta, 2010). 
Active behaviour change safety interventions in the construction industry:

\section{A systematic review}

Table 2. Methodological assessment of randomised and non-randomised studies

\begin{tabular}{|c|c|c|c|c|c|c|c|c|c|c|c|c|}
\hline Study & $\begin{array}{c}\text { Attempt } \\
\text { made to } \\
\text { blind study } \\
\text { participants } \\
\text { to received } \\
\text { intervention }\end{array}$ & $\begin{array}{c}\text { Attempt } \\
\text { made to } \\
\text { blind } \\
\text { outcome } \\
\text { assessors } \\
\text { measuring } \\
\text { intervention } \\
\end{array}$ & 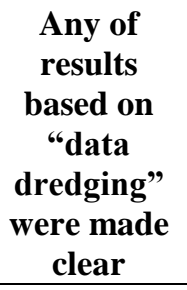 & $\begin{array}{l}\text { Analyses } \\
\text { adjusted } \\
\text { for } \\
\text { different } \\
\text { follow-up } \\
\text { lengths } \\
\end{array}$ & $\begin{array}{l}\text { Appropriate } \\
\text { statistical } \\
\text { tests used to } \\
\text { assess main } \\
\text { outcomes } \\
\end{array}$ & $\begin{array}{c}\text { Reliable } \\
\text { compliance } \\
\text { with } \\
\text { intervention } \\
\end{array}$ & $\begin{array}{c}\text { Accurate } \\
\text { use of main } \\
\text { outcome } \\
\text { measures }\end{array}$ & $\begin{array}{l}\text { Participant } \\
\text { recruitment } \\
\text { in different } \\
\text { intervention } \\
\text { groups were } \\
\text { from same } \\
\text { population }\end{array}$ & $\begin{array}{c}\text { Participants } \\
\text { in different } \\
\text { intervention } \\
\text { groups were } \\
\text { recruited } \\
\text { over same } \\
\text { time period } \\
\end{array}$ & $\begin{array}{c}\text { Participants } \\
\text { were } \\
\text { randomised } \\
\text { to } \\
\text { intervention } \\
\text { groups } \\
\end{array}$ & $\begin{array}{c}\text { Loss of } \\
\text { participants } \\
\text { follow-up } \\
\text { taken into } \\
\text { account } \\
\end{array}$ & Total \\
\hline $\begin{array}{l}\text { Adams } \\
\text { (2013) }\end{array}$ & Yes & Yes & Yes & Yes & Yes & Yes & Yes & Yes & Yes & Yes & Yes & $11 / 11$ \\
\hline $\begin{array}{l}\text { Becker } \\
(2001)\end{array}$ & $\begin{array}{l}\text { Unable to } \\
\text { determine }\end{array}$ & No & Yes & Yes & $\begin{array}{l}\text { Unable to } \\
\text { determine }\end{array}$ & No & $\begin{array}{l}\text { Unable to } \\
\text { determine }\end{array}$ & Yes & Yes & No & $\begin{array}{l}\text { Unable to } \\
\text { determine }\end{array}$ & $4 / 11$ \\
\hline $\begin{array}{l}\text { Bena } \\
(2009)\end{array}$ & No & No & Yes & Yes & Yes & No & Yes & No & No & No & $\begin{array}{l}\text { Unable to } \\
\text { determine }\end{array}$ & $4 / 11$ \\
\hline $\begin{array}{l}\text { Forst } \\
(2013)\end{array}$ & No & No & $\begin{array}{l}\text { Unable to } \\
\text { determine }\end{array}$ & No & Yes & Yes & Yes & Yes & No & No & No & $4 / 11$ \\
\hline $\begin{array}{l}\text { Kerr } \\
(2007)\end{array}$ & $\begin{array}{l}\text { Unable to } \\
\text { determine }\end{array}$ & $\begin{array}{l}\text { Unable to } \\
\text { determine }\end{array}$ & Yes & Yes & Yes & Yes & Yes & Yes & Yes & Yes & Yes & $9 / 11$ \\
\hline $\begin{array}{l}\text { Kines } \\
(2013)\end{array}$ & $\begin{array}{l}\text { Unable to } \\
\text { determine }\end{array}$ & No & Yes & Yes & Yes & Yes & Yes & Yes & Yes & Yes & Yes & $9 / 11$ \\
\hline $\begin{array}{l}\text { Kines } \\
(2010)\end{array}$ & No & No & Yes & Yes & Yes & Yes & Yes & Yes & Yes & $\begin{array}{l}\text { Unable to } \\
\text { determine }\end{array}$ & Yes & $8 / 11$ \\
\hline $\begin{array}{l}\text { Lopez- } \\
\text { Ruiz } \\
\text { (2013) }\end{array}$ & $\begin{array}{l}\text { Unable to } \\
\text { determine }\end{array}$ & No & Yes & Yes & Yes & Yes & Yes & Yes & Yes & No & $\begin{array}{l}\text { Unable to } \\
\text { determine }\end{array}$ & $7 / 11$ \\
\hline $\begin{array}{l}\text { Lusk } \\
\text { (1999) }\end{array}$ & $\begin{array}{l}\text { Unable to } \\
\text { determine }\end{array}$ & No & No & Yes & Yes & Yes & Yes & $\begin{array}{l}\text { Unable to } \\
\text { determine }\end{array}$ & $\begin{array}{l}\text { Unable to } \\
\text { determine }\end{array}$ & Yes & Yes & $6 / 11$ \\
\hline $\begin{array}{l}\text { Mancini } \\
(2005)\end{array}$ & $\begin{array}{l}\text { Unable to } \\
\text { determine }\end{array}$ & $\begin{array}{l}\text { Unable to } \\
\text { determine }\end{array}$ & Yes & Yes & Yes & $\begin{array}{l}\text { Unable to } \\
\text { determine }\end{array}$ & Yes & Yes & Yes & No & No & $6 / 11$ \\
\hline $\begin{array}{l}\text { Sokas } \\
(2009)\end{array}$ & No & No & $\begin{array}{l}\text { Unable to } \\
\text { determine }\end{array}$ & Yes & Yes & Yes & Yes & No & No & No & Yes & $5 / 11$ \\
\hline
\end{tabular}


Active behaviour change safety interventions in the construction industry:

\section{A systematic review}

Table 3. EPOC methodological quality assessment of ITS studies

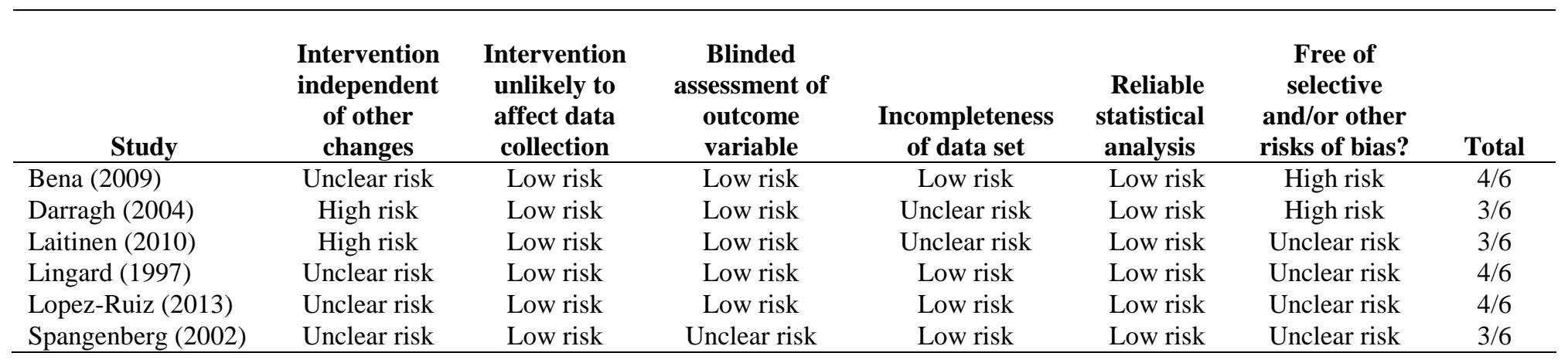




\section{Active behaviour change safety interventions in the construction industry:}

\section{A systematic review}

\section{DISCUSSION}

The purpose of this review was to evaluate the effectiveness of active, behaviour change safety interventions in the construction industry, with a particular focus on determining the intervention characteristics associated with successful injury reduction/improved safety behaviour. Although most of the interventions that measured injuries did result in reductions in the intervention groups, methodological issues such as the lack of a control group and non-equivalence of conditions at baseline make it difficult to draw firm conclusions about effectiveness. Despite this, several factors did appear to be differentially related to the likelihood of success. Firstly, single session interventions were less effective than those that extended over longer periods, suggesting that future interventions should utilise long-term change strategies rather than single educational/informational sessions. Further, it was found that the removal of the active intervention resulted in the previously observed improvements plateauing or a return to previous injury rates/safety behaviour. Although based on only two studies (Laitinen \& Päivärinta, 2010; Lingard \& Rowlinson, 1997), this pattern strongly suggests that lasting change in the areas of safety and injury prevention is dependent upon encouraging the development of intrinsic motivation (i.e., motivated by enjoyment/interest in the task itself or its natural consequences rather than extrinsic motivation: motivated only by the prospect of an external reward/punishment) within construction workers rather than relying on short-term interventions to prompt and maintain positive workplace behaviour.

Research has found that behaviour change interventions based on theory tend to produce larger effects than those that lack a theoretical basis (Webb et al., 2010). In the current review, only a third of the interventions mentioned a theoretical 


\section{Active behaviour change safety interventions in the construction industry:}

\section{A systematic review}

framework; only one used the theory to inform the intervention targets and methods, and measured the components of the theory pre- and post-intervention (Kerr et al., 2007). This is consistent with research in other health behaviours, where it has been found that while many studies mention theory in the introduction, or measure the theoretical components, rarely is the theory explicitly used to select intervention targets or methods (Hardeman et al., 2002; Michie \& Abraham, 2004; Michie \& Prestwich, 2010). Interestingly, however, the one study that was truly theory-based (Kerr et al., 2007) was not only amongst the higher quality studies, but also resulted in significant improvements in the use of hearing protection devices and demonstrated that the theory did indeed account for significant variance in the target behaviour, suggesting that the application of theory to interventions in the construction field is an important future direction.

Interventions that included active BCTs such as monitoring, feedback and goal setting were more likely to be effective than those that relied on providing information about health consequences or how to perform the behaviour. Similarly, studies that used rewards, incentives and punishment were more effective than those that merely provided information; however, the limited evidence also suggested that these strategies worked best when combined with feedback and monitoring. These findings are consistent with the extensive body of literature on the gap between knowledge/intention and actual behaviour (Hornik, 1989; Sheeran, 2002), and suggest that strategies aimed at improving actual behaviour and ways to translate positive intention/knowledge into action rather than strategies to improve worker's motivation/intention to engage in safety behaviours are more likely to result in successful behaviour change amongst construction workers. 


\section{Active behaviour change safety interventions in the construction industry:}

\section{A systematic review}

It is widely known that behaviour change interventions based on inducing fear are only effective when also combined with techniques to improve self-efficacy (Peters, Ruiter, \& Kok, 2013; Witte \& Allen, 2000). Consistent with this, a study based on the extended parallel process model that was excluded from this review because it was laboratory-based rather than involving construction workers in a reallife setting (Basil, Basil, Deshpande, \& Lavack, 2013), found that fear was highest when threat messages contained low self-efficacy, whereas the inclusion of selfefficacy lowered fear ratings and improved attitudes. Although this study did not include a measure of actual behaviour, its positive results suggest that in order for interventions containing information on health consequences (including fear) to be effective in improving safety behaviour and reducing injury rates, techniques to boost self-efficacy are needed. Indeed, the one study in this review that did measure selfefficacy found a significant improvement from pre- to post-intervention (Kerr et al., 2007), suggesting that efficacy can be successfully targeted in construction.

The present findings are also broadly consistent with the previous reviews (Lehtola et al., 2008; van der Molen et al., 2012), in that the evidence suggests that passive interventions that do not actively involve workers in behaviour change have limited effectiveness. A further reason why the interventions that used BCTs designed to change knowledge and attitudes may not have worked is that, in the absence of formative theory-driven research to determine the factors associated with noncompliance, it was unclear whether poor knowledge and/or negative attitudes were indeed causally related to behaviour/injury rates. The observation that monitoring alone (i.e., without feedback) also resulted in significant reductions in injury rates, may provide a potential solution as to how to promote lasting behaviour change 


\section{Active behaviour change safety interventions in the construction industry:}

\section{A systematic review}

amongst workers following intervention participation (although there is limited evidence to suggest that monitoring alone is sufficient), without relying on extrinsic motivation (i.e., rewards) which are unlikely to lead to internalisation of the desired behaviour.

Regarding the improved adoption of safety behaviours, the results were less clear than those concerning injury rates. None of the intervention characteristics (theory-base, BCTs, intensity/duration/frequency) reliably differentiated between effective and non-effective interventions because all interventions resulted in at least one improvement. Significant differences in the targeted behaviours and measurement also made comparisons difficult. Despite this, it is likely that the findings for injury rates (which were more uniformly measured) are also relevant considerations for future intervention design.

Overall, these results suggest that the evidence for the effectiveness of safety interventions in the construction industry is sparse and inconsistent. Further, the available interventions were generally poorly designed, which limited the conclusions that could be drawn from the data - for example, many studies lacked a control/comparison group and those that did were often not equivalent at baseline or were drawn from a different population than the intervention. While improvements in study design and evaluation are clearly needed to allow for firm conclusions regarding effectiveness to be drawn, it should be noted, however, that the dynamic and constantly changing nature of the construction industry means that RCT designs with individual-level randomisation (typically considered the gold standard and necessary for obtaining level 1 evidence) are unlikely to be practical or valid in this context. Similarly, it may be unrealistic to expect that behaviour change be independent of 


\section{Active behaviour change safety interventions in the construction industry:}

\section{A systematic review}

other changes or that reporting practices themselves do not impact injury rates and safety behaviour. Despite such contextual considerations, however, more methodologically rigorous but feasible and field-appropriate research is needed to determine the most effective means for improving safety and reducing injuries in the construction industry.

\subsection{Limitations and conclusions}

In addition to the identified limitations of the reviewed literature, there were limitations to the current review such as the inclusion of only published material and therefore potential exclusion of government or other documents and grey literature, and limiting the search to the English language. Finally, it was not possible to conduct a meta-analysis due to the heterogeneity in methods used to assess and describe injury rates as well as differences in the mechanism hypothesised to be responsible for the observed changes. Nonetheless, tentative recommendations that emerged from the available data, and previous evidence suggesting that the introduction of safety legislation/regulation is not sufficient (Lehtola et al., 2008; van der Molen et al., 2012), include the need for the conduct of formative theory-driven research to determine the significant predictors of poor workplace safety behaviour and the occurrence of workplace injuries; more rigorous and consistent use of theory in intervention design; the adoption of active/volitional BCTs; and the implementation of long-term strategies that overcome the limited effectiveness of single session interventions and also encourage the adoption of intrinsic rather than extrinsic motivation for continuing safe behaviour. Finally, the systematic testing of such interventions using RCT designs (albeit with site-level rather than individual-level randomisation) is necessary to determine the most effective means for reducing the 
Active behaviour change safety interventions in the construction industry:

A systematic review

negative impact that inadequate workplace safety has on society at the individual, site, and economic levels.

Acknowledgements and funding: This work was supported under the Australian Research Council's Linkage Projects Scheme (project number LP110100220) in collaboration with WorkCover Authority NSW.

Competing interests: The authors declare that there is no conflict of interest. 
Active behaviour change safety interventions in the construction industry:

\section{A systematic review}

\section{REFERENCES}

Adams, J. S., Raju, R., Solomon, V., Samuel, P., Dutta, A. K., Rose, J. S., \& Tharyan, P. (2013). Increasing compliance with protective eyewear to reduce ocular injuries in stone-quarry workers in Tamil Nadu, India: A pragmatic, cluster randomised trial of a single education session versus an enhanced education package delivered over six months. Inj., 44, 118-125. doi:10.1016/j.injury.2011.10.001

Aires, M. D. M., Gamez, M. C. R., \& Gibb, A. (2010). Prevention through design: The effect of European directives on construction workplace accidents. Saf. Sci., 48, 248-258. doi:10.1016/j.ssci.2009.09.004

Basil, M., Basil, D., Deshpande, S., \& Lavack, A. M. (2013). Applying the Extended Parallel Process Model to workplace safety messages. Health Commun., 28(1), 29-39. doi:10.1080/10410236.2012.708632

Beal, A. N. (2007). CDM regulations: 12 years of pain but little gain. Civ. Eng., 160, 82-88. doi:10.1680/cien.2007.160.2.82

Becker, P., Fullen, M., Akladios, M., \& Hobbs, G. (2001). Prevention of construction falls by organizational intervention. Inj. Prev., 7(Suppl 1), i64-i67. doi:10.1136/ip.7.suppl_1.i64

Bena, A., Berchialla, P., Coffano, M. E., Debernardi, M. L., \& Icardi, L. G. (2009). Effectiveness of the training program for workers at construction sites of the high-speed railway line between Torino and Novara: Impact on injury rates. Am. J. Ind. Med., 52(12), 965-972. doi:10.1002/ajim.20770 


\section{Active behaviour change safety interventions in the construction industry:}

\section{A systematic review}

Darragh, A. R., Stallones, L., Bigelow, P. L., \& Keefe, T. J. (2004). Effectiveness of the HomeSafe Pilot Program in reducing injury rates among residential construction workers, 1994-1998. Am. J. Ind. Med., 45(2), 210-217. doi:10.1002/ajim.10339

Downs, S. H., \& Black, N. (1998). The feasibility of creating a checklist for the assessment of the methodological quality both of randomised and nonrandomised studies of health care interventions. J. Epidemiol. Community Health, 52(6), 377-384. doi:10.1136/jech.52.6.377

EPOC. (2009). Effective practice and organisation of care review group data collection checklist. Retrieved from http://epoc.cochrane.org/sites/epoc.cochrane.org/files/uploads/datacollectionch ecklist.pdf.

Forst, L., Ahonen, E., Zanoni, J., Holloway-Beth, A., Oschner, M., Kimmel, L., . . . Skoas, R. (2013). More than training: Community-based participatory research to reduce injuries among hispanic construction workers. Am. J. Ind. Med., 56(8), 827-837. doi:10.1002/ajim.22187

Hardeman, W., Johnston, M., Johnston, D., Bonetti, D., Wareham, N., \& Kinmonth, A. L. (2002). Application of the theory of planned behaviour in behaviour change interventions: A systematic review. Psychol. Health, 17(2), 123-158. doi:10.1080/08870440290013644

Health and Safety Executive. (2013). The Health and Safety Executive Statistics: 2012-2013. Retrieved from http://www.hse.gov.uk/statistics/

Higgins, J. P., \& Green, S. (2008). Cochrane handbook for systematic reviews of interventions (Vol. 5): Wiley Online Library. 


\section{Active behaviour change safety interventions in the construction industry:}

\section{A systematic review}

Higgins, J. P. T., \& Green, S. (Eds.). (2011). Cochrane Handbook for Systematic Reviews of Interventions (Vol. Version 5.1.0, updated March 2011): The Cochrane Collaboration.

Hornik, R. (1989). The knowledge-behaviour gap in public information campaigns: A development communication view. In C. T. Salmon (Ed.), Information campaigns: Balancing social values and social change (pp. 113-138). Newbury Park, CA: Sage.

International Labour Organization. (2011). Global trends and challenges on occupational safety and health. Turkey: International Labour Office

Kerr, M. J., Savik, K., Monsen, K. A., \& Lusk, S. L. (2007). Effectiveness of computer-based tailoring versus targeting to promote use of hearing protection. Can. J. Nurs. Res., 39(1), 80-97. Retrieved from http://ezproxy.library.usyd.edu.au/login?url=http://ovidsp.ovid.com/ovidweb.c gi?T=JS\&CSC $=$ Y \&NEWS=N\&PAGE=fulltext $\& D=$ psyc5\&AN=2007-04799006

http://DD8GH5YX7K.search.serialssolutions.com/?sid=OVID:psycdb\&id=pmid:\&id =doi: \&issn=0844-5621\&isbn=\&volume=39\&issue=1\&spage=80\&pages=80$97 \&$ date $=2007 \&$ title $=$ CJNR $\% 3 \mathrm{~A}+$ Canadian + Journal + of + Nursing + Research $\&$ atitle=Effectiveness + of + computerbased+tailoring+versus+targeting+to+promote+use+of+hearing+protection.\& aulast $=$ Kerr

Kines, P., Andersen, D., Andersen, L. P., Nielsen, K., \& Pedersen, L. (2013). Improving safety in small enterprises through an integrated safety 


\section{Active behaviour change safety interventions in the construction industry:}

\section{A systematic review}

management intervention. J. Saf. Res., 44(1), 87-95.

doi:10.1016/j.jsr.2012.08.022

Kines, P., Andersen, L. P. S., Spangenberg, S., Mikkelsen, K. L., Dyreborg, J., \& Zohar, D. (2010). Improving construction site safety through leader-based verbal safety communication. J. Saf. Res., 41(5), 399-406. doi:10.1016/j.jsr.2010.06.005

Kothe, E. J., Mullan, B. A., \& Butow, P. (2012). Promoting fruit and vegetable consumption: Testing an intervention based on the theory of planned behaviour. Appet., 58(3), 997-1004.

Laitinen, H., \& Päivärinta, K. (2010). A new-generation safety contest in the construction industry - A long-term evaluation of a real-life intervention. Saf. Sci., 48(5), 680-686. doi:10.1016/j.ssci.2010.01.018

Lehtola, M. M., van der Molen, H. F., Lappalainen, J., Hoonakker, P. L. T., Hsiao, H., Haslam, R. A., . . . Verbeek, J. H. (2008). The effectiveness of interventions for preventing injuries in the construction industry: A systematic review. Am. J. Prev. Med., 35(1), 77-85. doi:10.1016/j.amepre.2008.03.030

Lingard, H., \& Rowlinson, S. (1997). Behavior-based safety management in Hong Kong's construction industry. J. Saf. Res., 28(4), 243-256. doi:10.1016/S0022$4375 \% 2897 \% 2900010-8$

Lipscomb, H. J., Li, L., \& Dement, J. (2003). Work-related falls among union carpenters in Washington State before and after the Vertical Fall Arrest Standard. Am J Ind Med, 44(2), 157-165. doi:10.1002/ajim.10254

Lopez-Ruiz, M., Martinez, J. M., Gil, J. M., Boix, P., Garcia, A. M., Rodrigo, F., . . Benavides, F. G. (2013). Evaluation of the effectiveness of occupational injury 


\section{Active behaviour change safety interventions in the construction industry:}

\section{A systematic review}

prevention programs at the company level. Saf. Sci., 51(1), 250-256.

doi:10.1016/j.ssci.2012.06.026

Lusk, S. L., Hong, O. S., Ronis, D. L., Eakin, B. L., Kerr, M. J., \& Early, M. R. (1999). Effectiveness of an intervention to increase construction workers' use of hearing protection. Hum. Factors, 41(3), 487-494. doi:10.1518/001872099779610969

Mancini, G., Baldasseroni, A., Laffi, G., Curti, S., Mattioli, S., \& Violante, F. S. (2005). Prevention of work related eye injuries: Long term assessment of the effectiveness of a multicomponent intervention among metal workers. Occup. Environ. Med., 62(12), 830-835. doi:10.1136/oem.2004.019570

Michie, S., \& Abraham, C. (2004). Interventions to change health behaviours: Evidence-based or evidence-inspired? Psychol. Health, 19(1), 29-49. doi:10.1080/0887044031000141199

Michie, S., \& Prestwich, A. (2010). Are interventions theory-based? Development of a theory coding scheme. Health Psychol., 29(1), 1-8. doi:10.1037/a0016939

Michie, S., Richardson, M., Johnston, M., Abraham, C., Francis, J. J., Hardeman, W., ... Wood, C. (2013). The Behaviour Change Technique Taxonomy (v1) of 93 hierarchically clustered techniques: Building an international consensus for the reporting of behaviour change interventions. Ann. Behav. Med., 46, 81-95. doi:10.1007/s12160-013-9486-6

Milton, A. C., \& Mullan, B. A. (2012). An application of the theory of planned behavior-A randomized controlled food safety pilot intervention for young adults. Health Psychol., 31(2), 250-259. doi:10.1037/a0025852 


\section{Active behaviour change safety interventions in the construction industry:}

\section{A systematic review}

Mirka, G. A., Monroe, M., Nay, T., Lipscomb, H., \& Kelaher, D. (2003). Ergonomic interventions for the reduction of low back stress in framing carpenters in the home building industry. Int. J. of Ind. Ergon., 31(6), 397-409. doi:10.1016/s0169-8141(03)00025-8

Miscetti, G., \& Bodo, P. (2008). Prevention of building site accidents in Umbria during reconstruction after an earthquake: The experience of one Local Health Unit Med. del Lavoro, 99, 136-144.

Moher, D., Liberati, A., Tetzlaff, J., \& Altman, D. (2009). Preferred reporting items for systematic reviews and meta-analyses: The PRISMA Statement. PLoS Med., 6(6), e1000097. doi:10.1371/journal.pmed.1000097

Mohr, D. L., \& Clemmer, D. I. (1989). Evaluation of an occupational injury intervention in the petroleum drilling industry. Accid. Anal. Prev., 21(3), 263271. doi:10.1016/0001-4575(89)90017-1

National Safety Council. (2013). Injury facts. Retrieved from Itasca, IL:

Peters, G.-J. Y., Ruiter, R. A. C., \& Kok, G. (2013). Threatening communication: A critical re-analysis and revised meta-analytic test of fear appeal theory. Health Psychol. Rev., 7, S8-S31. doi:10.1080/17437199.2012.703527

Ramsay, C., Matowe, L., Grilli, R., Grimshaw, J., \& Thomas, R. (2003). Interrupted time series designs in health technology assessment: Lessons from two systematic reviews of behavior change strategies. International Journal of Technology Assessment in Health Care, 19, 613-623.

Rivara, F. P., \& Thompson, D. C. (2000). Prevention of falls in the construction industry: Evidence for program effectiveness. Am. J. Prev. Med., 18(4), 23-26. doi:10.1016/s0749-3797(00)00137-9 


\section{Active behaviour change safety interventions in the construction industry:}

\section{A systematic review}

Sainsbury, K., Mullan, B. A., \& Sharpe, L. (2013). A randomized controlled trial of an online intervention to improve gluten-free diet adherence in celiac disease. Am. J. Gastroenterol, 108, 811-817. doi:10.1038/ajg.2013.47

Saruda, A., Whitaker, B., Bloswick, D., Philips, P., \& Sesek, R. (2002). Impact of the OSHA trench and evacuation standard on fatal injury in the construction industry. Occup. Environ. Med., 44(10), 902-905. doi:10.1097/01.jom.0000031924.77204.83

Sheeran, P. (2002). Intention-behavior relations: A conceptual and empirical review. Eur. Rev. Soc. Psychol., 12(1), 1-36. doi:10.1080/14792772143000003

Sokas, R. K., Jorgensen, E., Nickels, L., Gao, W. H., \& Gittleman, J. K. (2009). An intervention effectiveness study of hazard awareness training in the construction building trades. Public Health Rep., 124(Suppl. 1), 161-168. Retrieved from <Go to ISI >://WOS:000266795600018

Spangenberg, S., Mikkelsen, K. L., Kines, P., Dyreborg, J., \& Baarts, C. (2002). The construction of the Øresund Link between Denmark and Sweden: The effect of a multi-faceted safety campaign. Saf. Sci., 40(5), 457-465. doi:0.1016/S0925-7535(01)00013-3

Tyers, C., Sinclair, A., Lucy, D., Cowling, M., Gordon-Dweagu, V., \& Rick, J. (2007). Constructing better health, final evaluation report. Health and Safety Executive, Research Report 565, 1-227.

van der Molen, H. F., Lehtola, M. M., Lappalainen, J., Hoonakker, P. L., Hsiao, H., Haslam, R., . . Verbeek, J. H. (2012). Interventions to prevent injuries in construction workers. Cochrane Database Syst. Rev., 12, CD006251. doi:10.1002/14651858.CD006251.pub3 
Active behaviour change safety interventions in the construction industry:

\section{A systematic review}

Webb, T. L., Joseph, J., Yardley, L., \& Michie, S. (2010). Using the internet to promote health behaviour change: A systematic review and meta-analysis of the impact of theoretical basis, use of behaviour change techniques, and mode of delivery on efficacy. Jour. Med. Internet Res., 12, e4. doi:10.2196/jmir.1376

Witte, K., \& Allen, M. (2000). A meta-analysis of fear appeals: Implications for effective public health campaigns. Health Educ. Behav., 27, 591-615. doi:10.1177/109019810002700506 


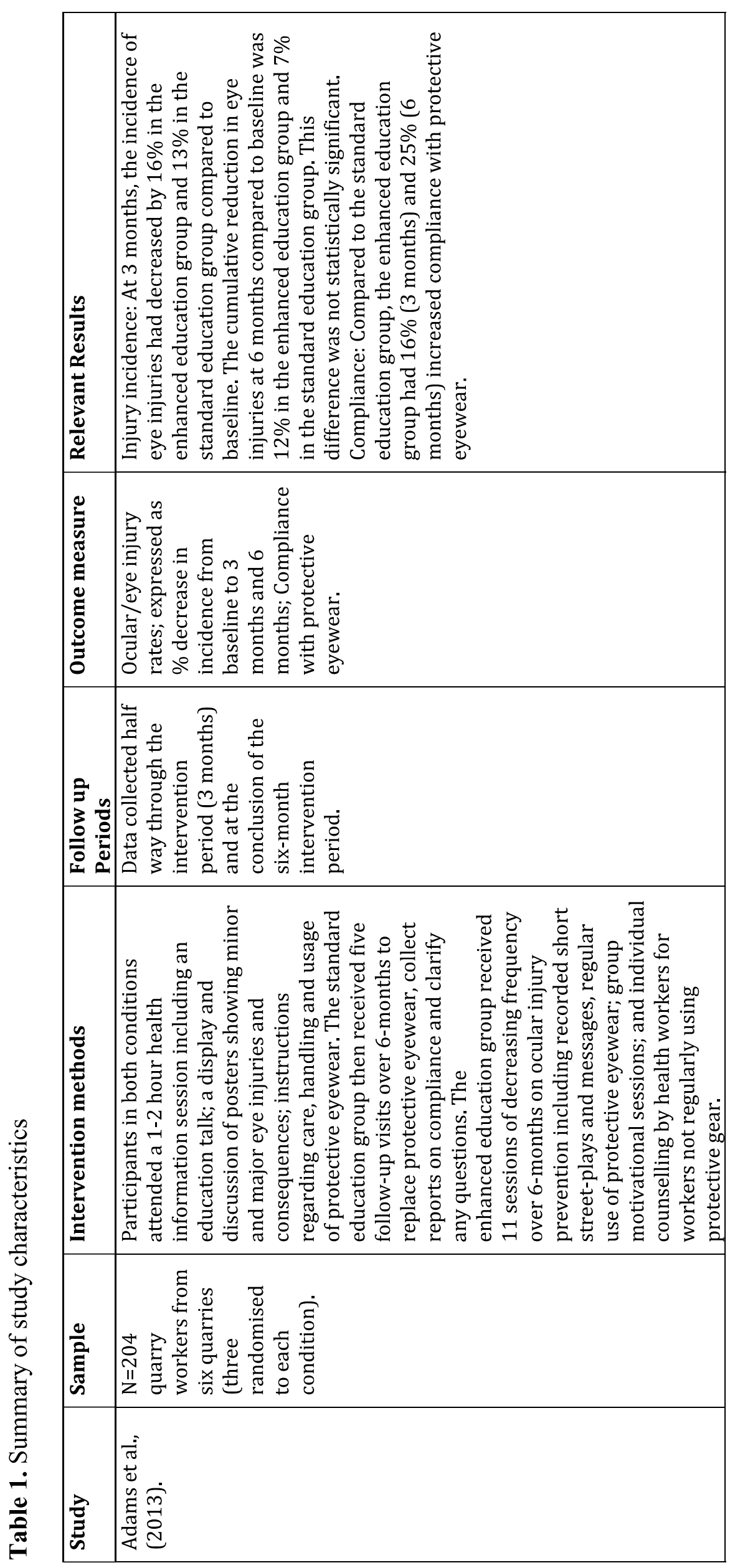




\begin{tabular}{|c|c|}
\hline 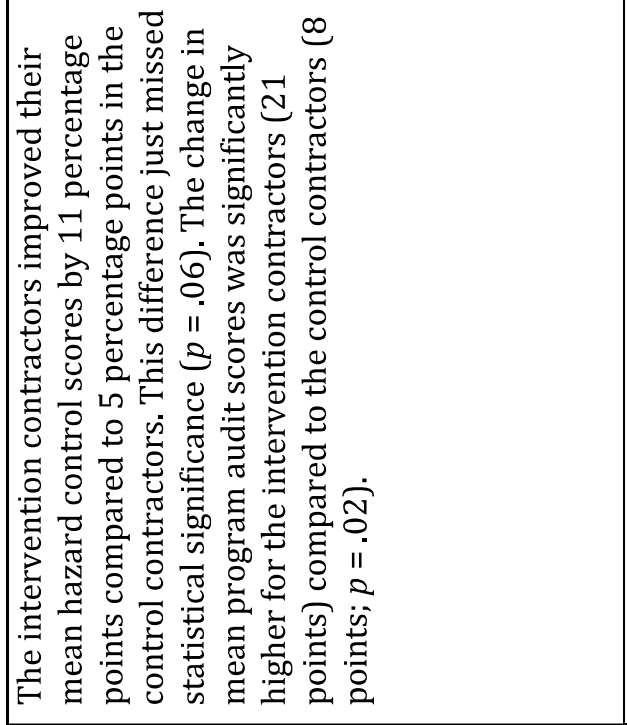 & 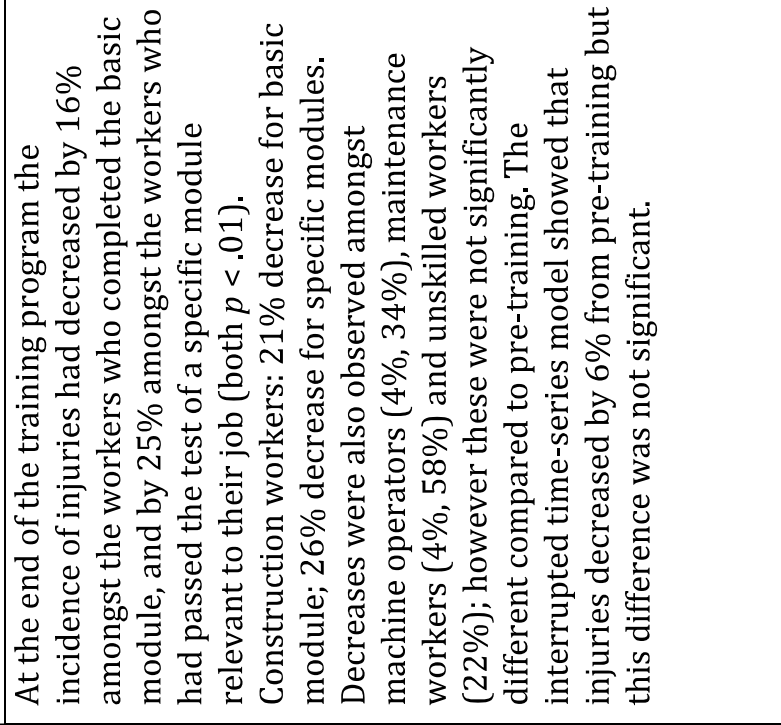 \\
\hline 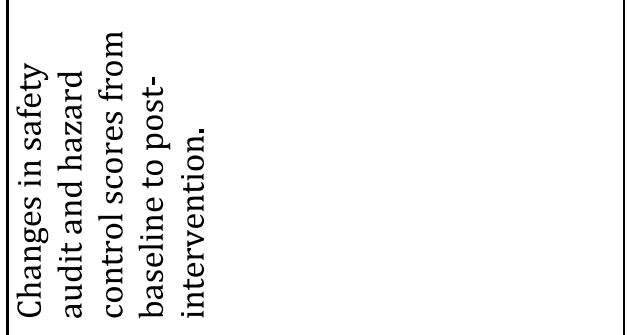 & 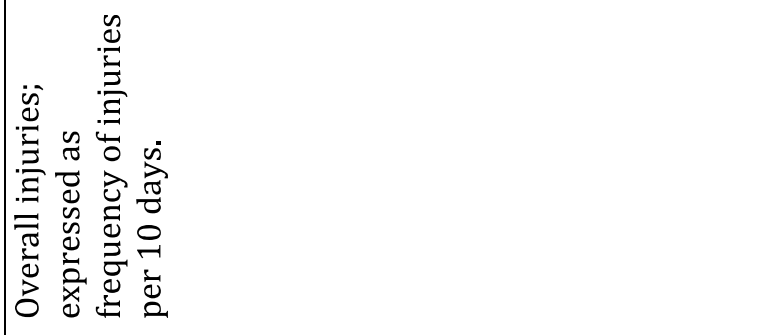 \\
\hline 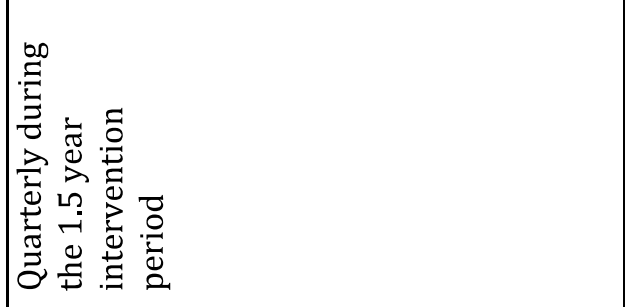 & 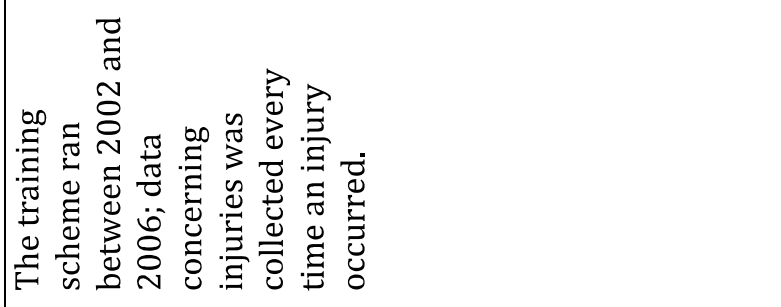 \\
\hline 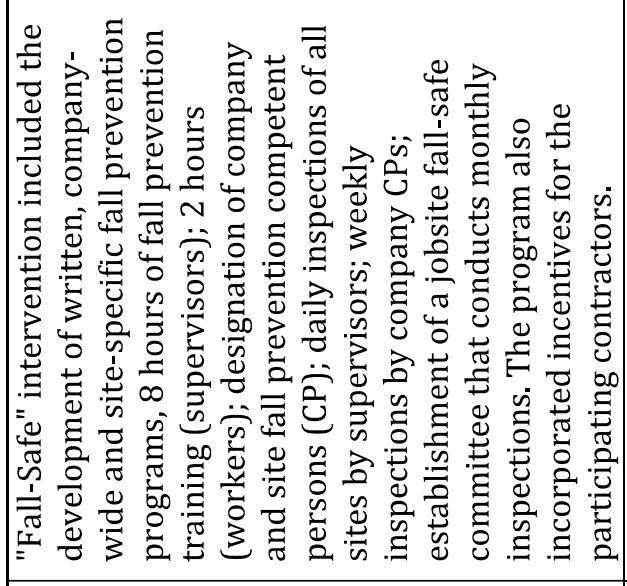 & 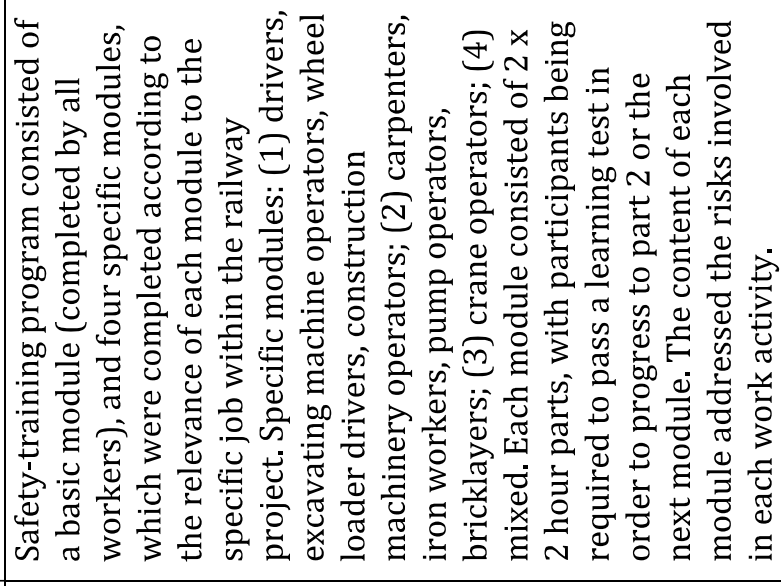 \\
\hline 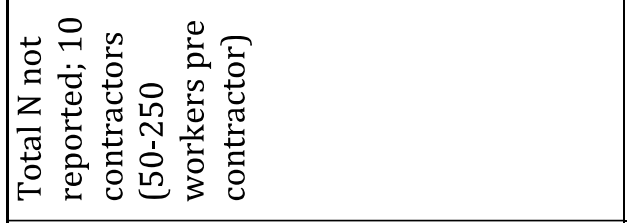 & \\
\hline 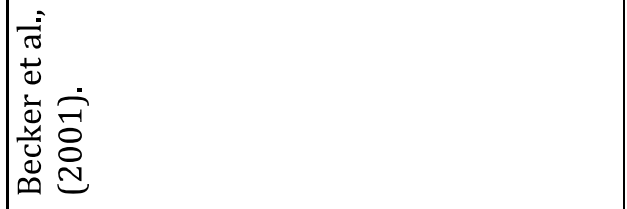 & 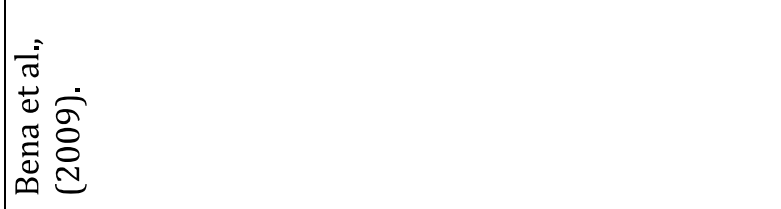 \\
\hline
\end{tabular}




\begin{tabular}{|c|c|}
\hline 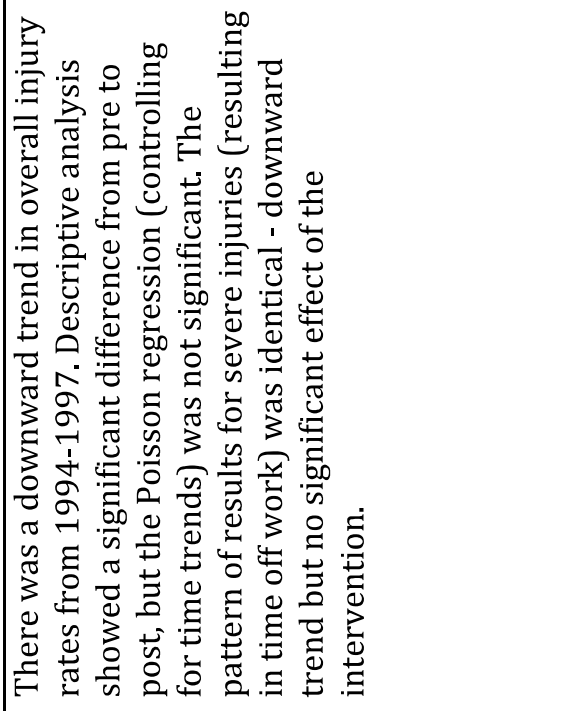 & 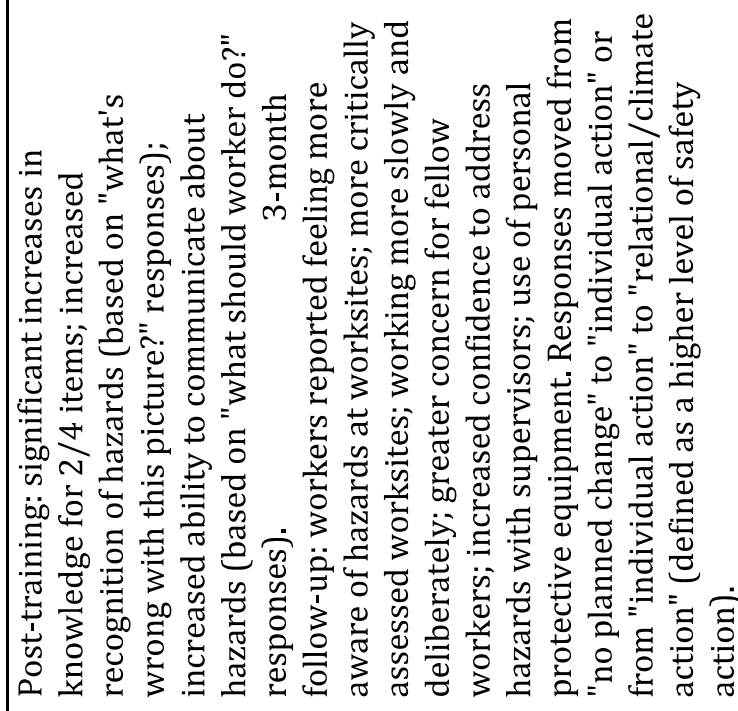 \\
\hline 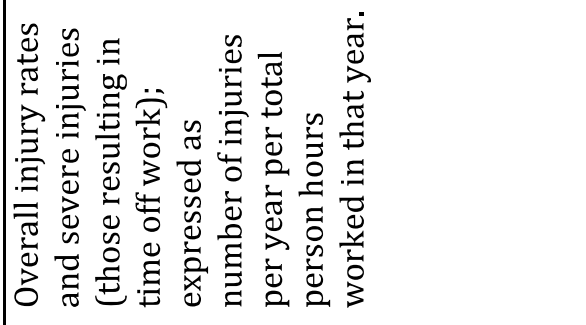 & 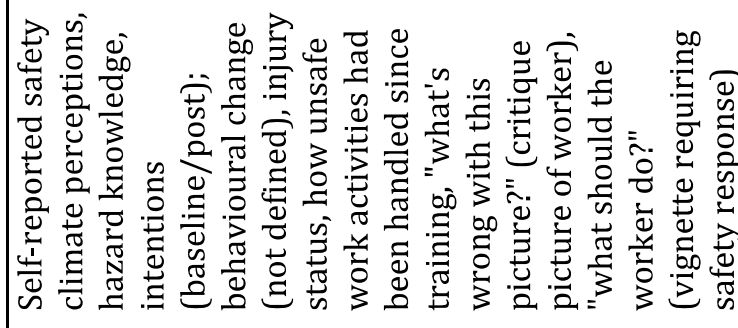 \\
\hline 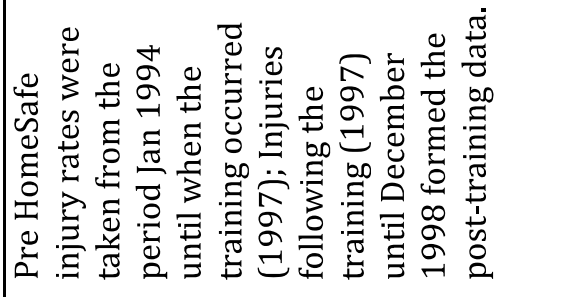 & 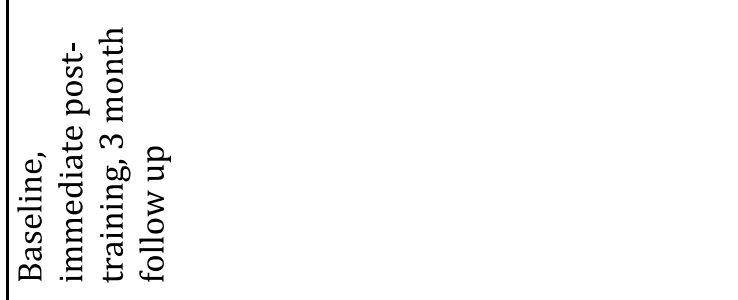 \\
\hline 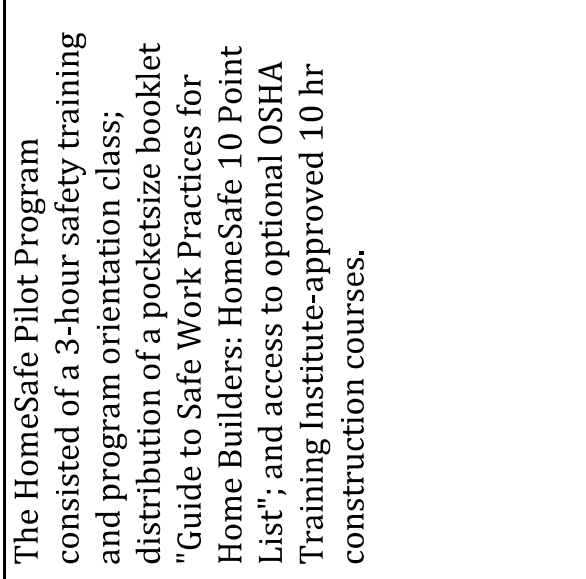 & 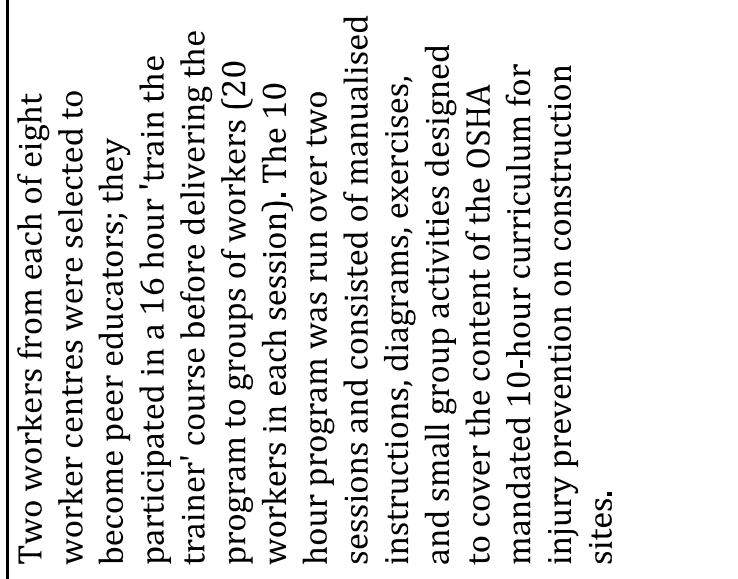 \\
\hline 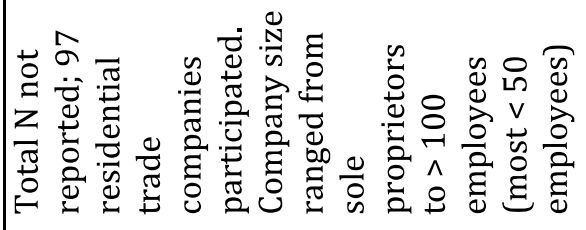 & \begin{tabular}{l}
0 \\
\multirow{2}{1}{} \\
11 \\
$z$
\end{tabular} \\
\hline 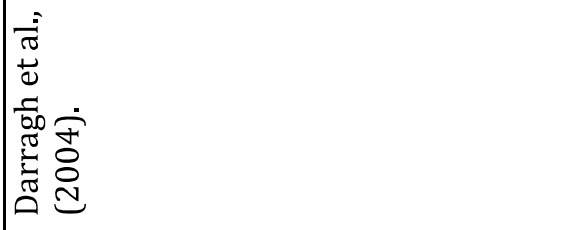 & 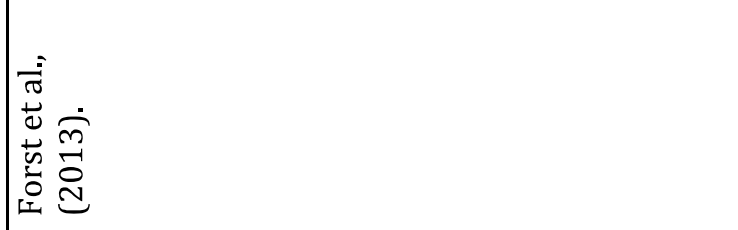 \\
\hline
\end{tabular}




\begin{tabular}{|c|c|}
\hline 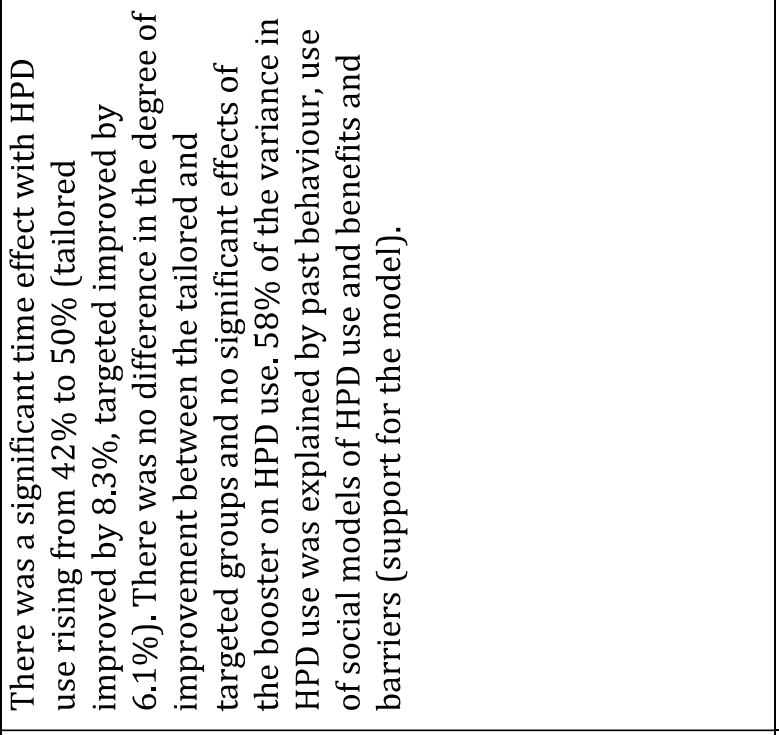 & 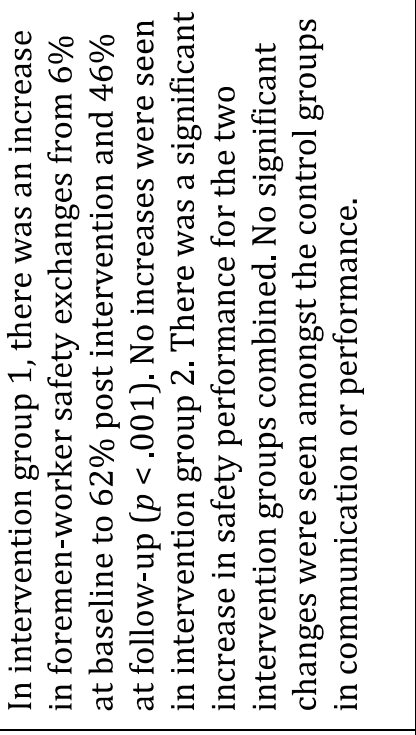 \\
\hline 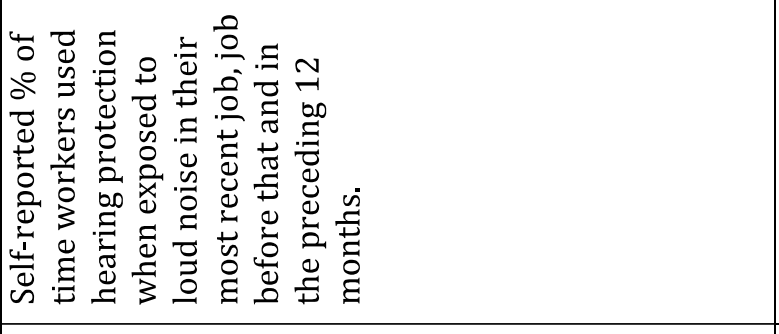 & 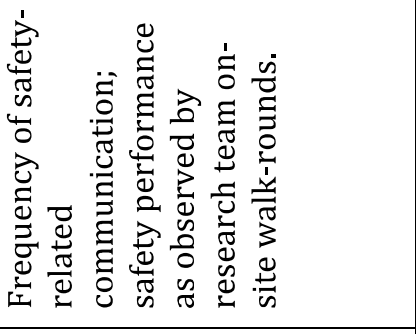 \\
\hline 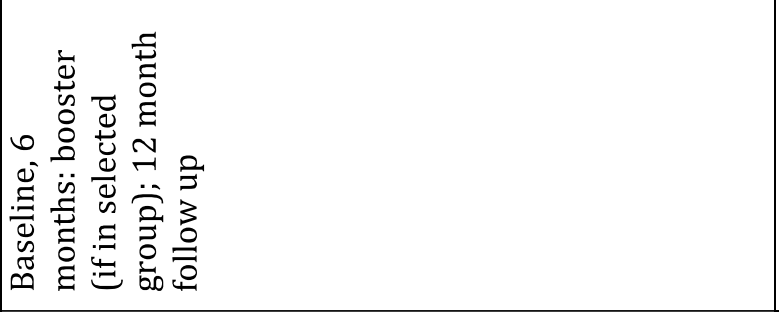 & 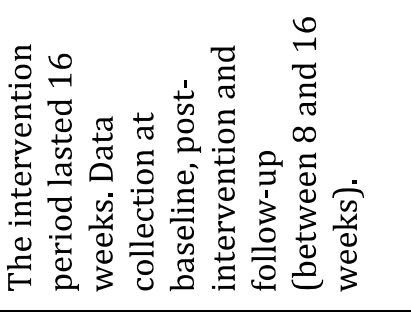 \\
\hline 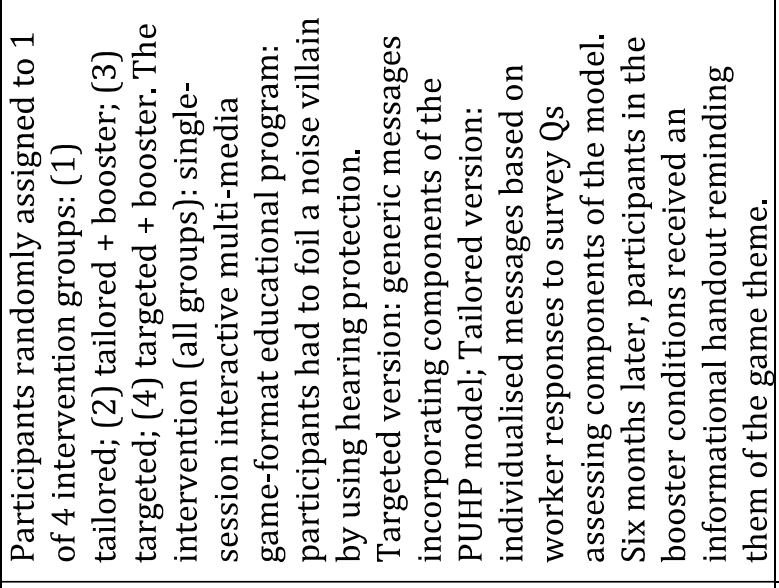 & 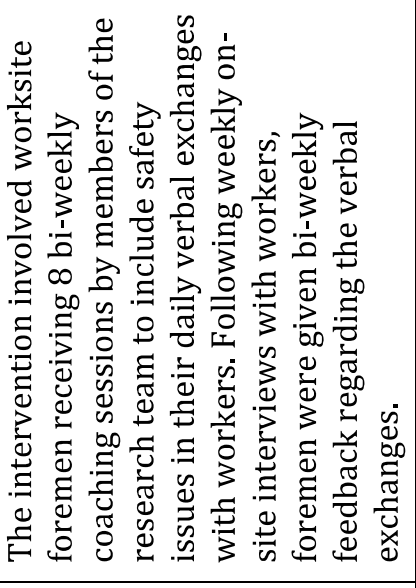 \\
\hline & 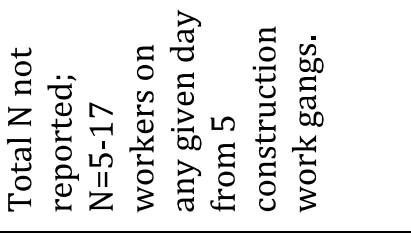 \\
\hline 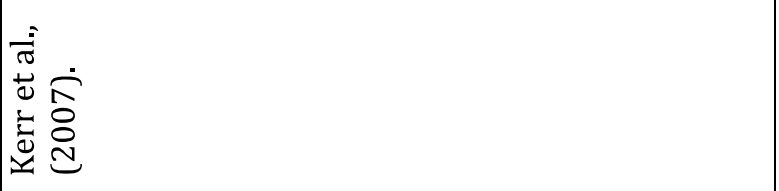 & 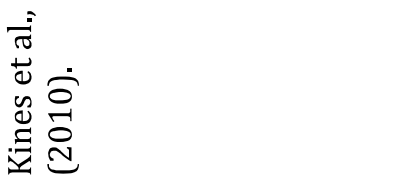 \\
\hline
\end{tabular}




\begin{tabular}{|c|c|}
\hline 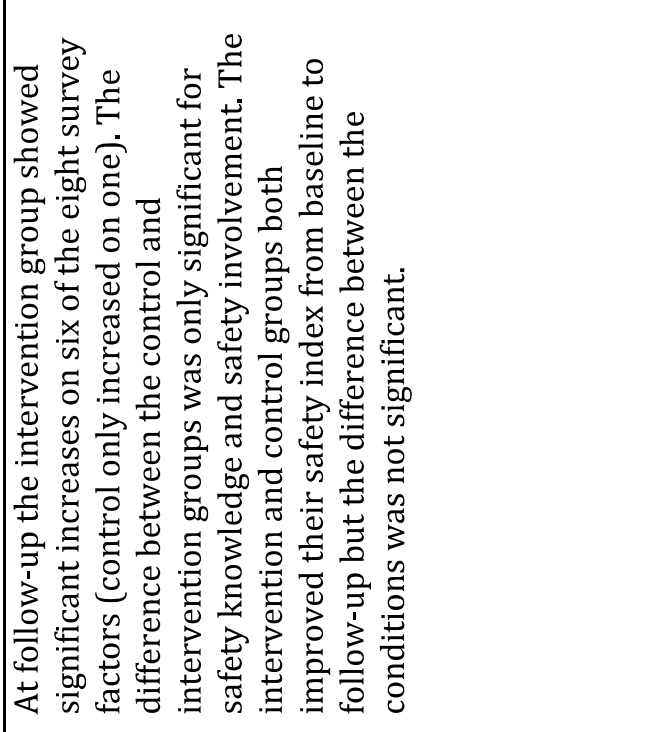 & 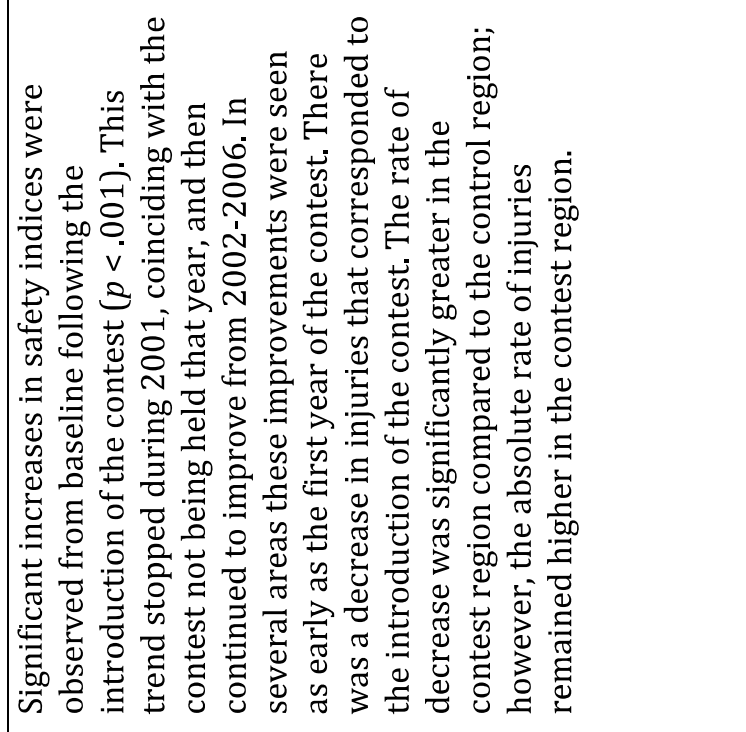 \\
\hline 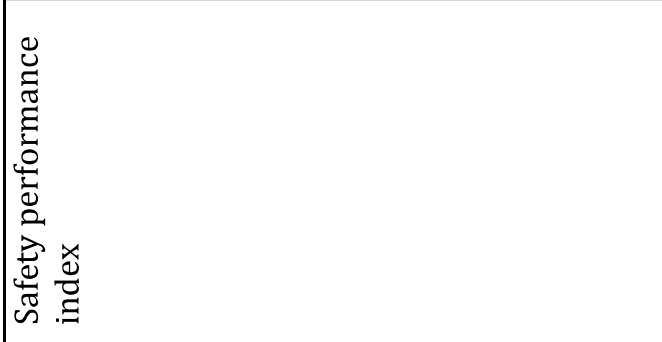 & 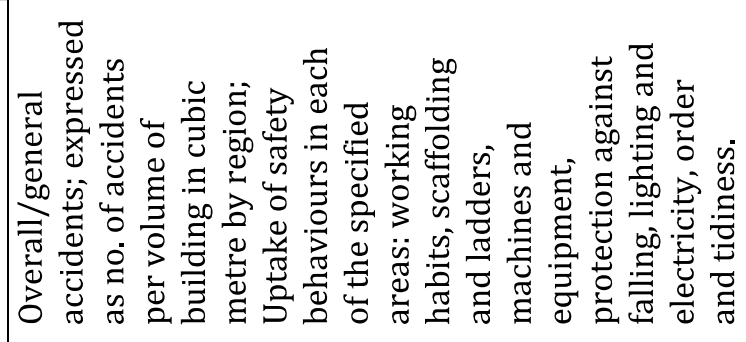 \\
\hline 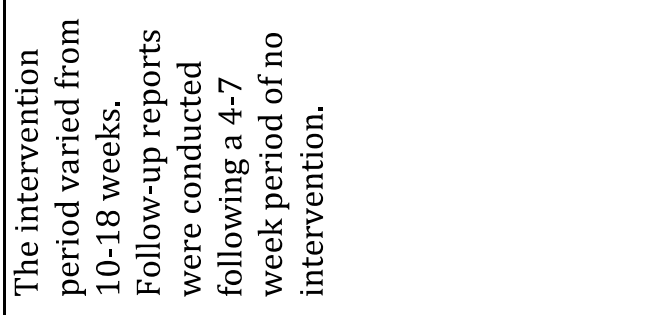 & 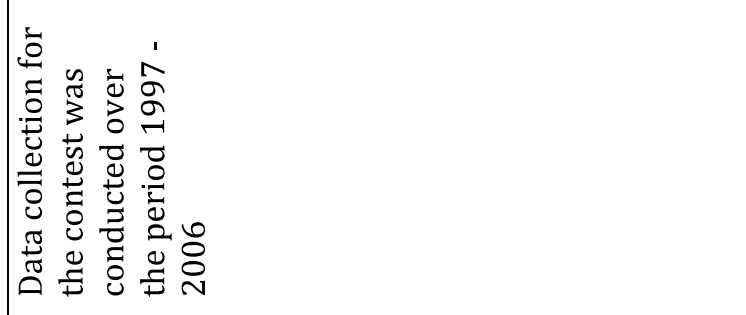 \\
\hline 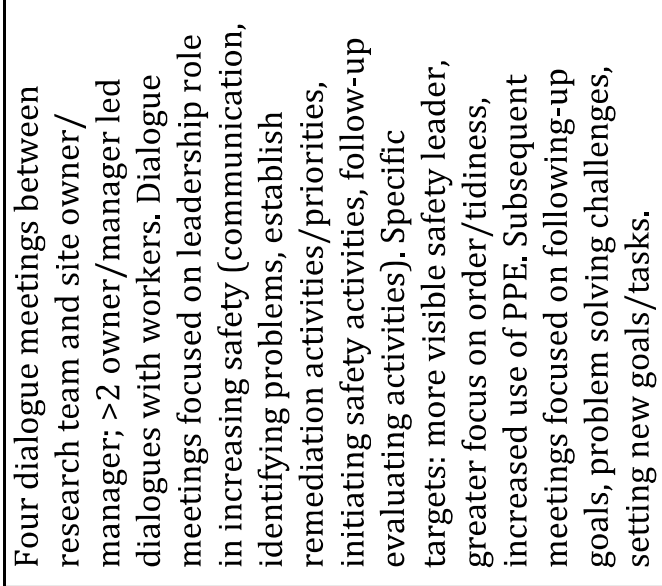 & 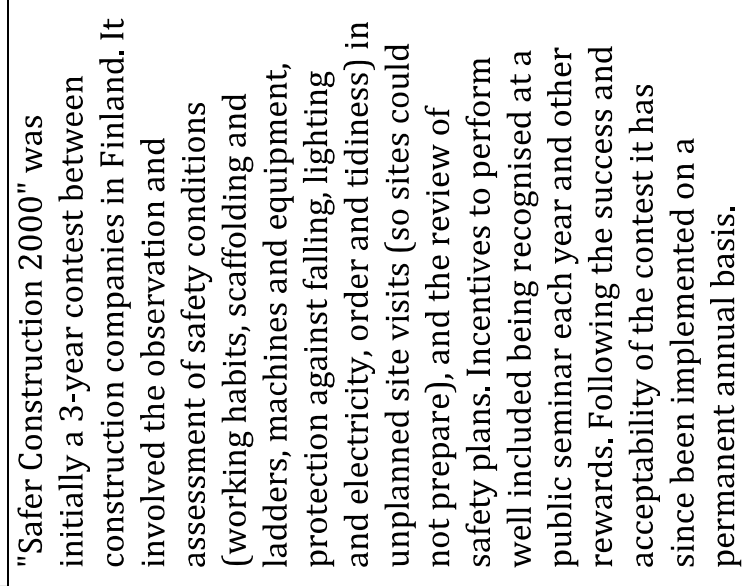 \\
\hline 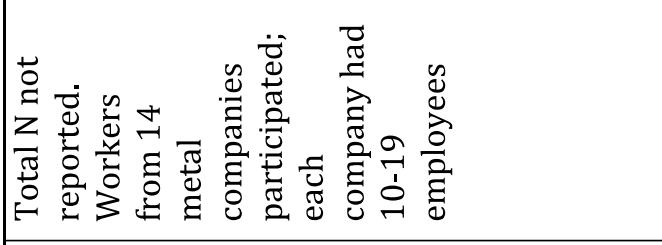 & 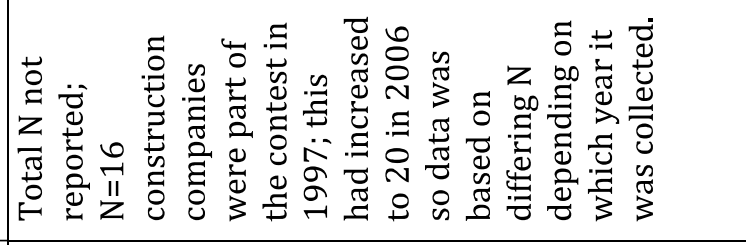 \\
\hline 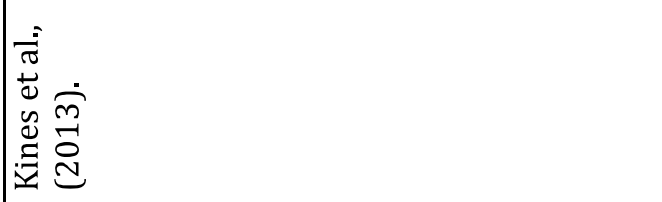 & 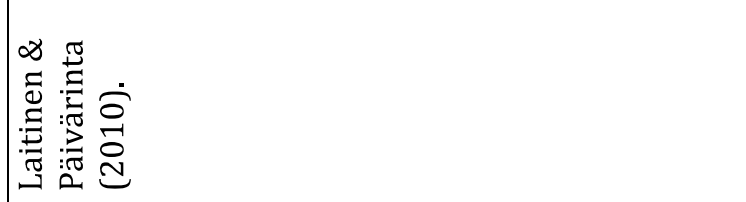 \\
\hline
\end{tabular}




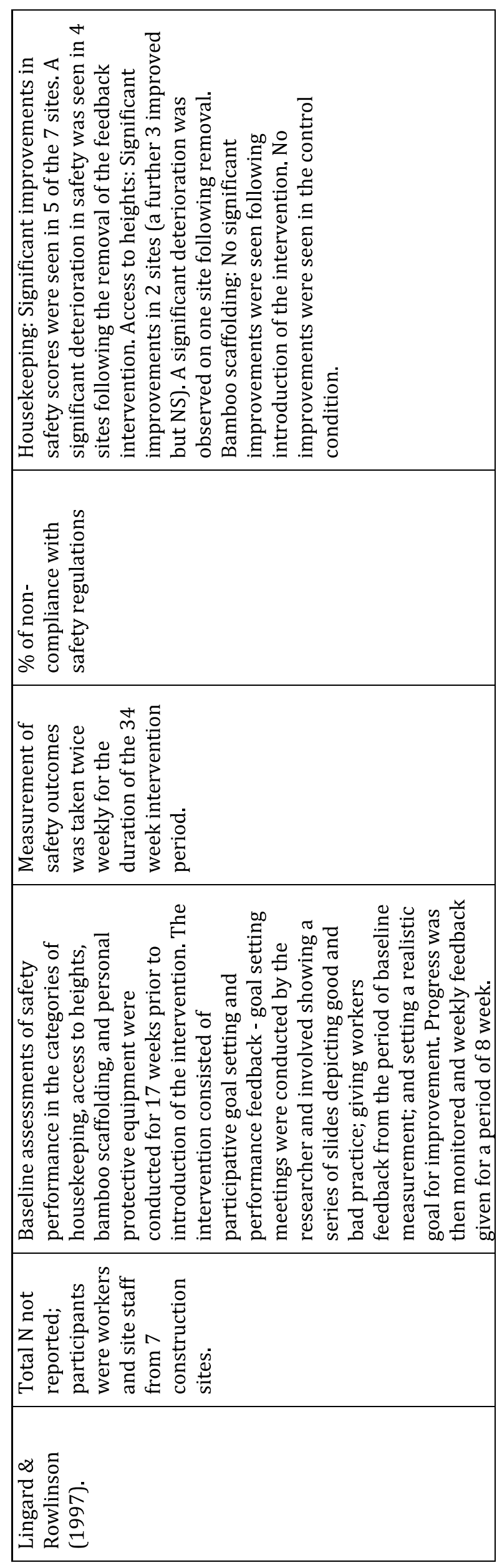




\begin{tabular}{|c|c|}
\hline 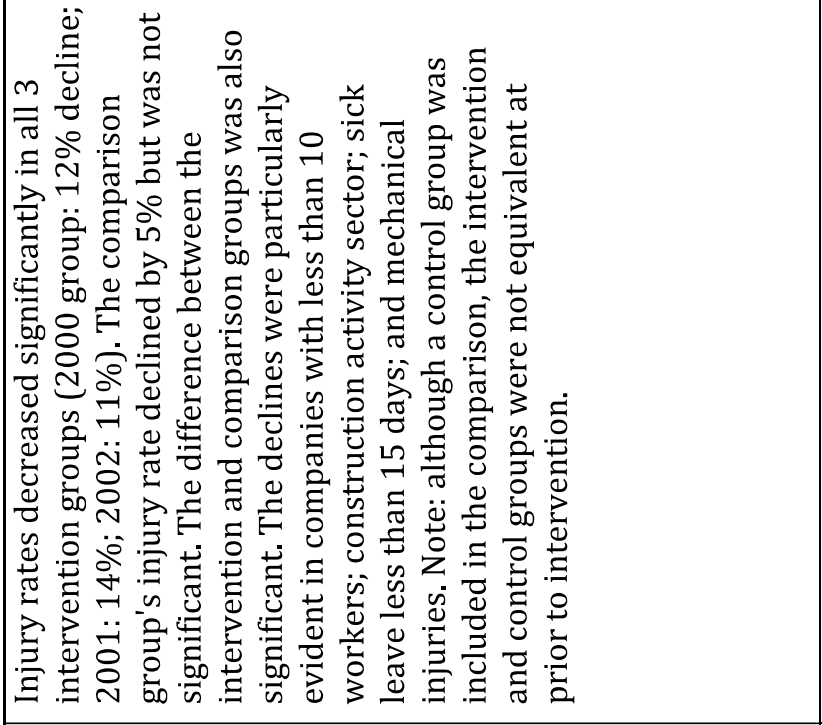 & 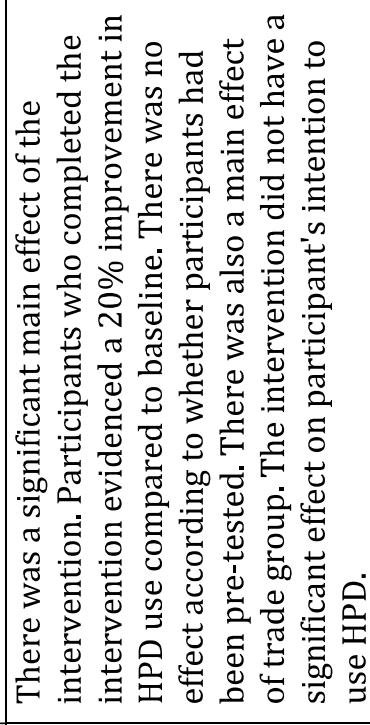 \\
\hline 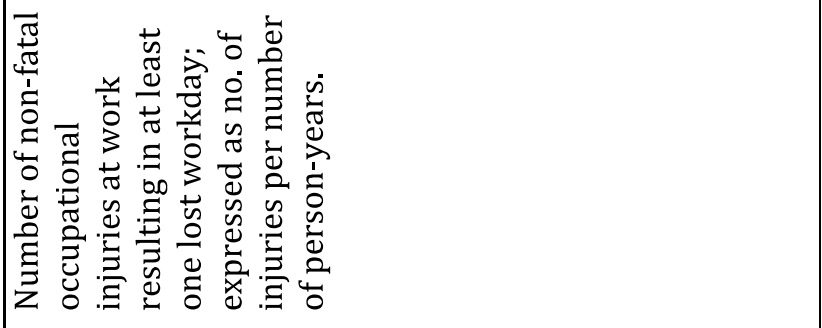 & 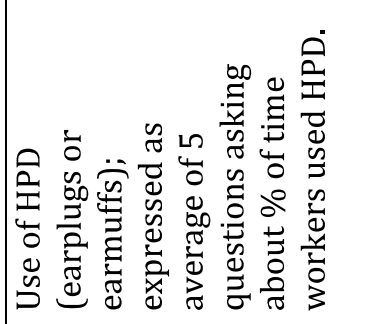 \\
\hline 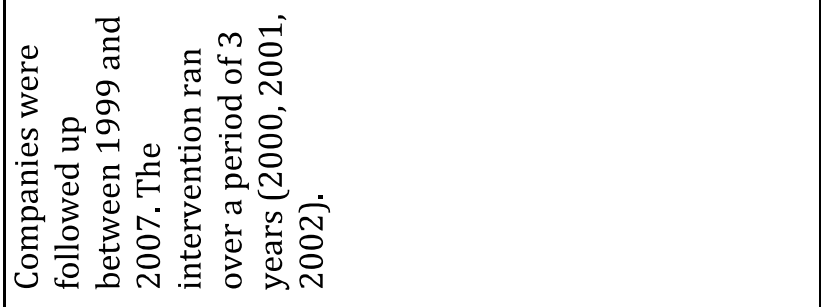 & 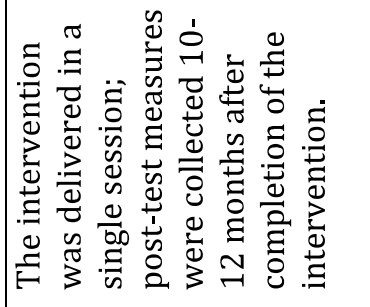 \\
\hline 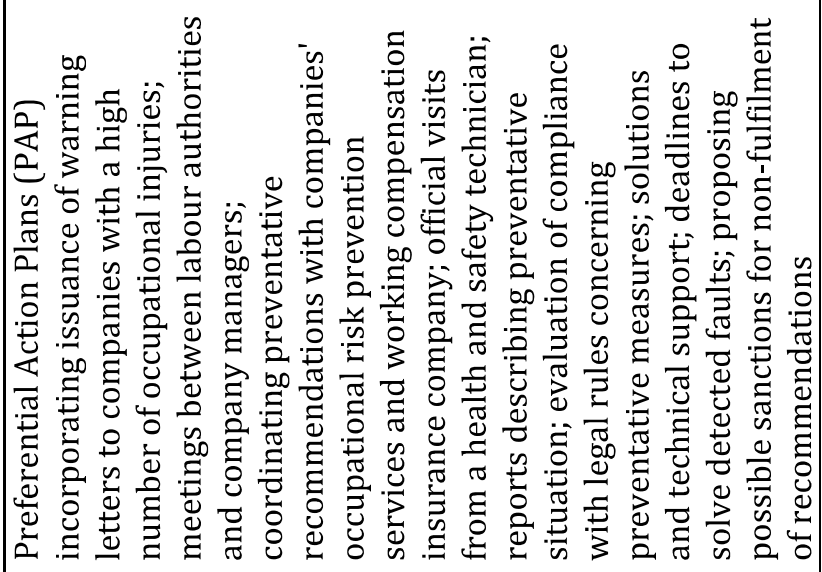 & 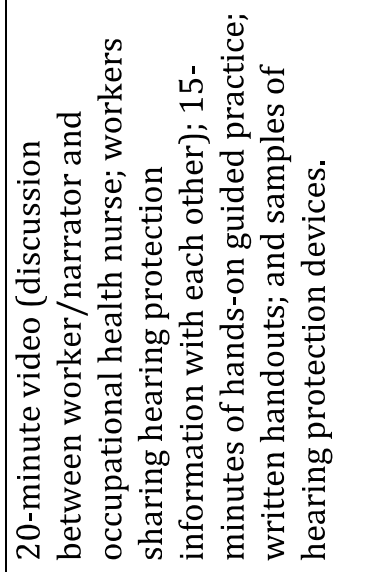 \\
\hline 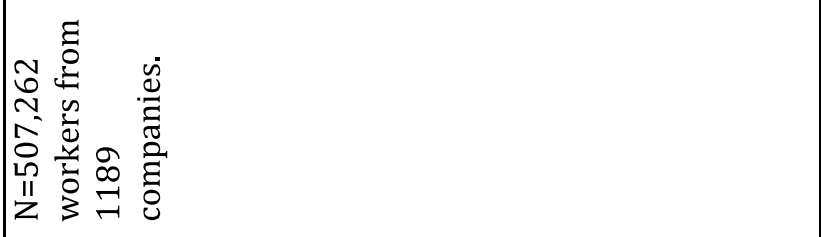 & 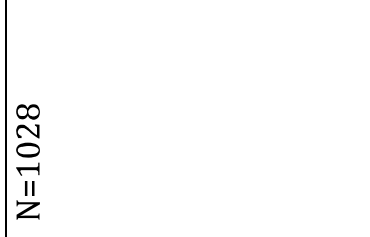 \\
\hline 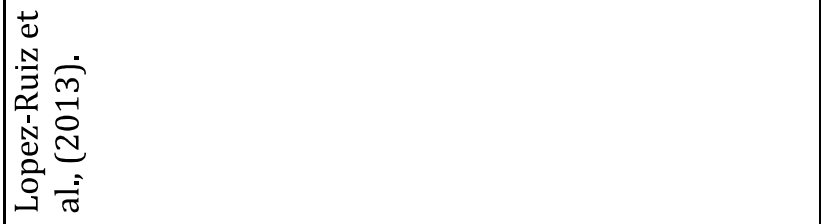 & 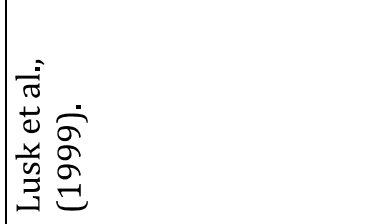 \\
\hline
\end{tabular}




\begin{tabular}{|c|c|}
\hline 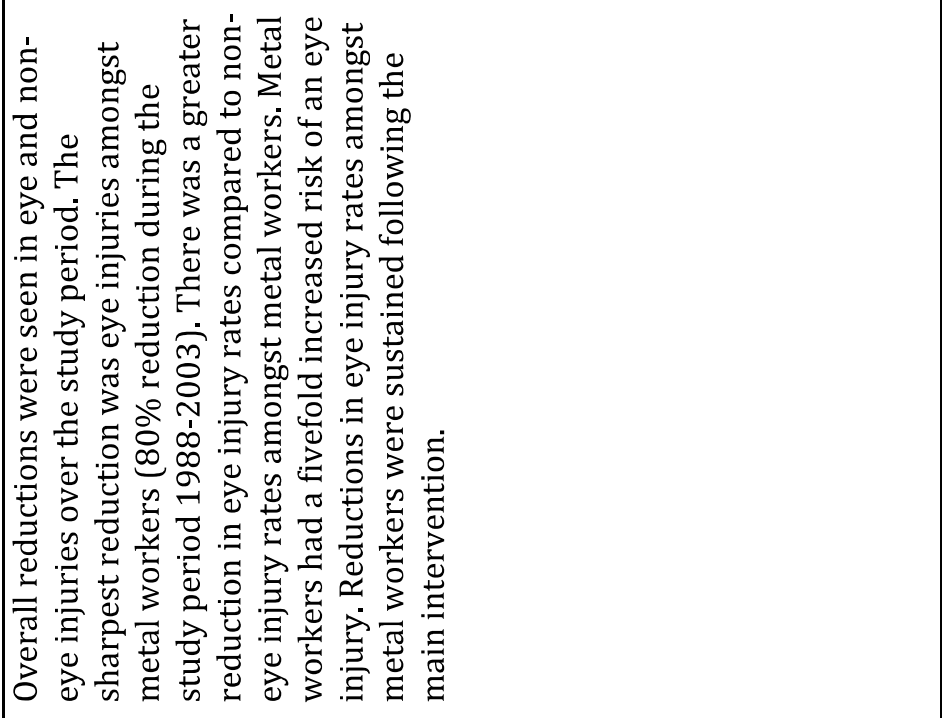 & 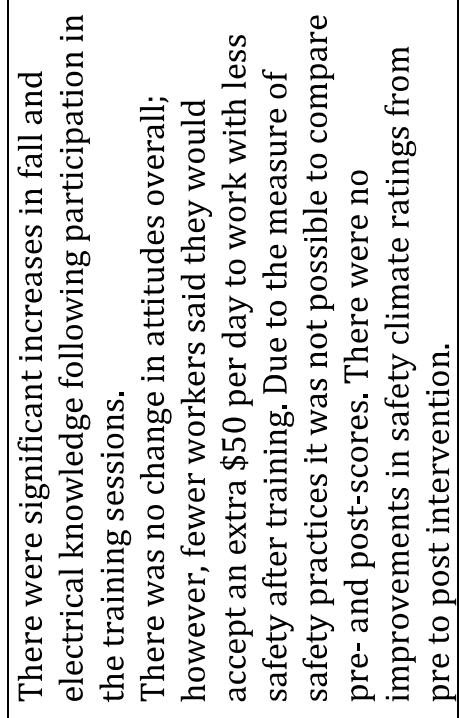 \\
\hline 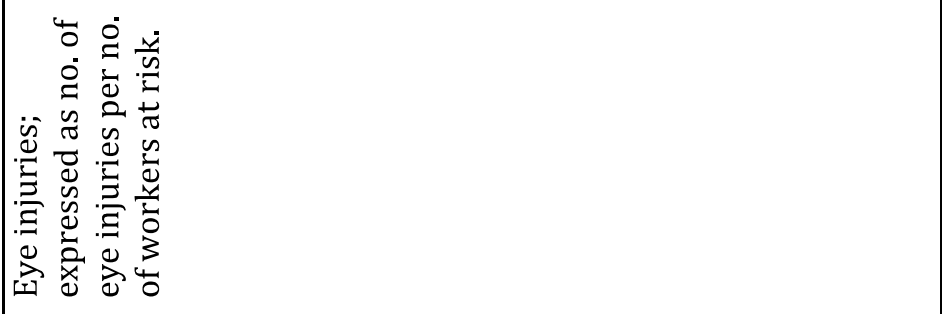 & 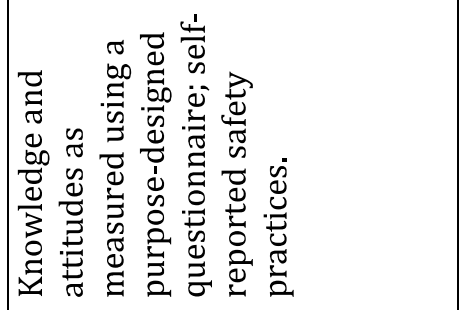 \\
\hline 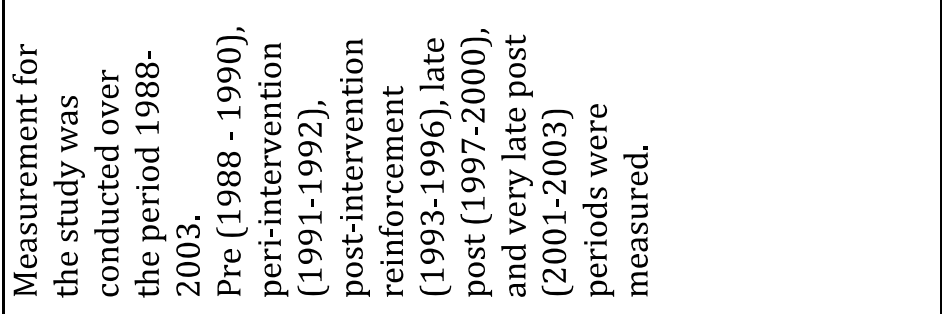 & 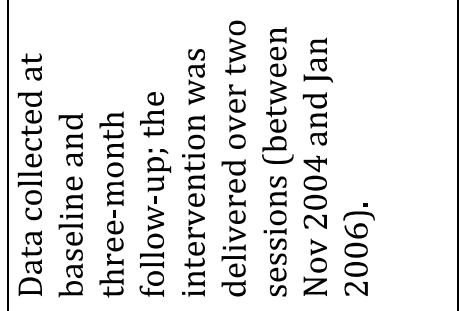 \\
\hline 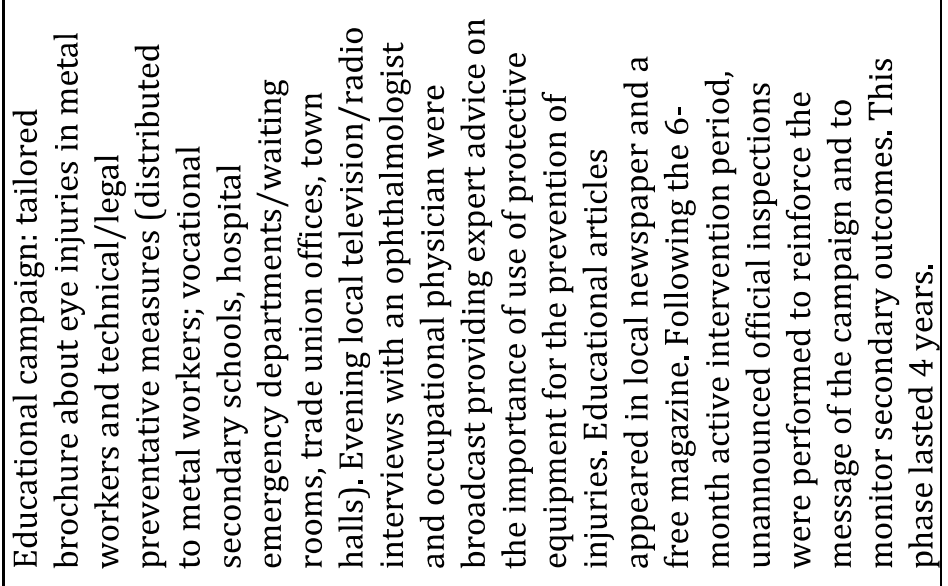 & 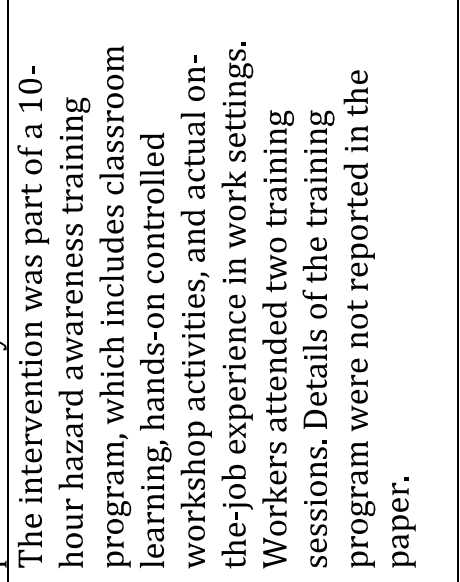 \\
\hline 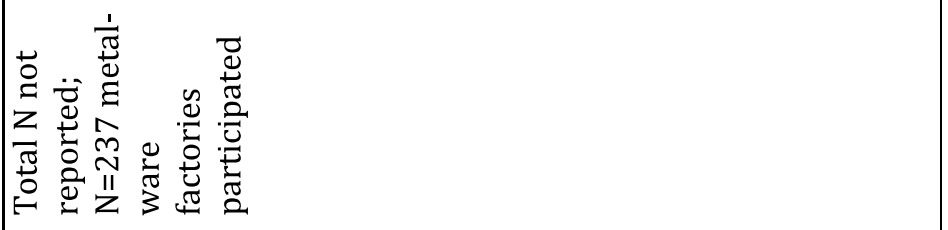 & 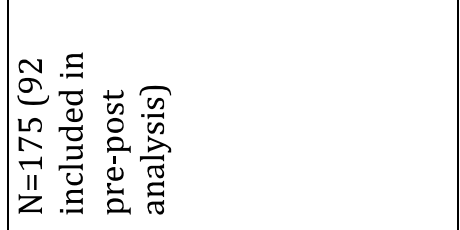 \\
\hline 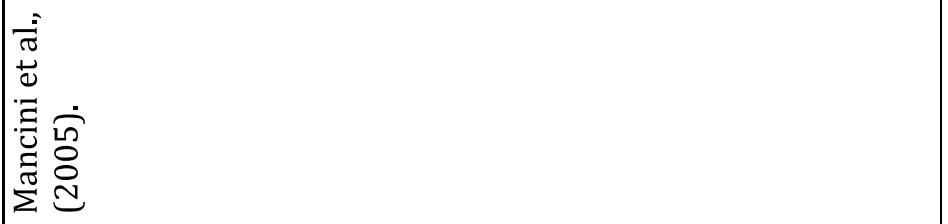 & 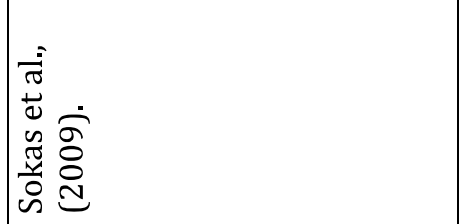 \\
\hline
\end{tabular}




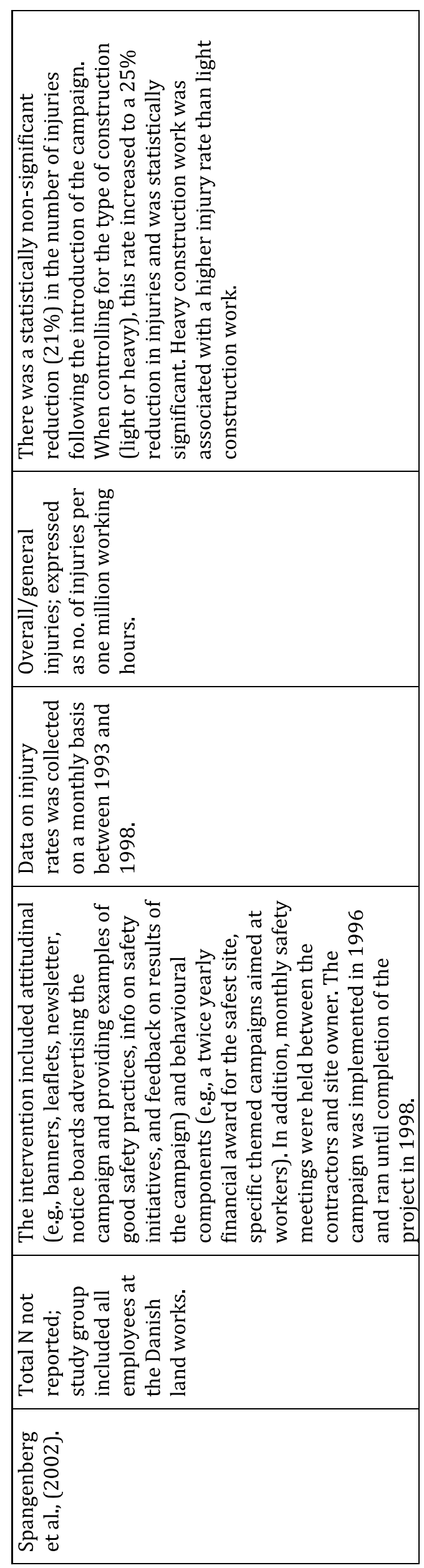

